\title{
Finite element simulations of stretch-blow moulding with experimental validation over a broad process window
}

\author{
J. Nixon ${ }^{1}\left(\right.$ D $\cdot$ G. H. Menary ${ }^{1} \cdot$ S. Yan $^{1}$
}

Received: 22 August 2016/Accepted: 26 September 2016 /Published online: 25 October 2016

(C) The Author(s) 2016. This article is published with open access at Springerlink.com

\begin{abstract}
Injection stretch blow moulding is a wellestablished method of forming thin-walled containers and has been extensively researched for numerous years. This paper is concerned with validating the finite element analysis of the free-stretch-blow process in an effort to progress the development of injection stretch blow moulding of poly(ethylene terephthalate). Extensive data was obtained experimentally over a wide process window accounting for material temperature and air flow rate, while capturing cavity pressure, stretch-rod reaction force and preform surface strain. This data was then used to assess the accuracy of the correlating FE simulation constructed using ABAQUS/Explicit solver and an appropriate viscoelastic material subroutine. Results reveal that the simulation is able to give good quantitative correlation for conditions where the deformation was predominantly equal biaxial whilst qualitative correlation was achievable when the mode of deformation was predominantly sequential biaxial. Overall the simulation was able to pick up the general trends of how the pressure, reaction force, strain rate and strain vary with the variation in preform temperature and air flow rate. The knowledge gained from these analyses provides insight into the mechanisms of bottle formation, subsequently improving the blow moulding simulation and allowing for reduction in future development costs.
\end{abstract}

Keywords ISBM · PET · Free-stretch-blow · DIC · FEA · ABAQUS/Explicit

J. Nixon

j.nixon@qub.ac.uk

1 School of Mechanical and Aerospace Engineering, Queen's University Belfast, Ashby Building, Stanmillis Road, Belfast BT9 $5 \mathrm{AH}, \mathrm{UK}$

\section{Introduction}

Research into the injection stretch blow moulding (ISBM) process regarding the formation of light-weight, thin-walled containers has been extensive over the past number of decades. The combination of stretching and pressure inflation of the poly(ethylene terephthalate) (PET) preform to create the desired bottle inherently increases the mechanical properties of the material along with other attributes such as barrier properties. This characteristic of PET occurs when the material is heated and stretched above its glass transition temperature $\left(\sim 80^{\circ} \mathrm{C}\right)$ to generate strain induced crystallisation. The amount of strain induced crystallisation depends on the amount of strain, the rate of strain and deformation mode [1-3]. Capturing the behaviour of PET for the deformations typical during the ISBM process is crucial to understanding the potential for optimisation of the preform/bottle design and maximising the cost reduction in time, energy and material. In an effort to further the amount of knowledge, understanding and optimisation, the goal of academic and industrial research groups has been to develop a reliable and robust simulation of the ISBM process in order to 'virtually' produce any desired bottle shape from any potential preform geometry using multiple possible process parameters. This simulation is generally constructed using some form of finite element (FE) solver and assessing the accuracy and potential is therefore critical.

Investigation into the ISBM process has been extensive for numerous years in attempt to reduce the nature of the 'shooting in the dark' approach associated with respect to the initial process parameters. Numerous attempts to instrument aspects of the blowing process reveals an insight into how the bottle forms within the mould; these parameters include internal pressure [4], preform bubble propagation [5] and mould contact [6]. Huang et al. [7] investigated the evolution of the bottle shape by applying a transparent mould and viewing the 
deformation with high speed imaging. Alternatively, a common exercise employed when examining the ISBM process is to remove the bottle mould and allow the preform to deform in free air i.e. free-stretch-blow (FSB) trials. Billon et al. [8] attempted to perform this analysis while recording the free deformation with a high speed camera. The preform deformation was found to be heavily influenced by the pre-blow timing, a parameter that relates the activation of pre-blow pressure to the point in time when the stretch-rod makes contact with the preform i.e. early pressure activation (advance) and late pressure activation (delay). Menary and Billon et al. [9] then took this process further by applying a simple grid pattern to the preform outer surface in an effort to evaluate the displacement of certain points on the preform and eventual yield strain values. This process was found to be quite cumbersome and laborious with a potential for inaccuracy in results. Previous research conducted by Nixon et al. $[10,11]$ as well as work by Zimmer et al. [12] has been able to demonstrate that accurate and reliable data that can be obtained by applying a speckle pattern to the preform surface and performing a stereoscopic digital image correlation (DIC) analyse on FSB experiments. In the work of Nixon et al., a Design of Experiments was constructed accounting for preform temperature and pressure inflation air flow rate. The cavity pressure and stretch-rod reaction force were recorded using an instrumented stretch rod and the hoop and axial strain values were obtained using a stereoscopic DIC analysis and VIC3D correlation software. The experimental results from this analysis will be used in this paper to validate a simulation of the process. This is the first time a comprehensive validation for a stretch-blow simulation will have been performed.

Predicting the deformation of the preform when forming the bottle has been investigated using suitable finite element (FE) solving methods; the accuracy of these simulations has proved to have varying success. Menary et al. [13] used the cavity pressure readings from free-blow trials to assess the simulations ability in predicting pressure and volume evolution. An air mass flow rate model, as opposed to a directly applied pressure, was found to be the most successful approach. The bottle thickness was also used by Menary et al. [14] to assess the accuracy of different material models within the simulation with results demonstrating that the Buckley material model was succesful. The simulation allows for a more scientific approach in optimising the input parameters for the ISBM process. Yang et al. [15] revealed that preform temperature as well as the blowing pressure could significantly affect the predicted final bottle characteristics and concluded that to produce a reliable simulation relies on analysing the process conditions as well as the preform temperature. Bordival et al. [16] also examined the effect of preform temperature during the simulation; where an optimum preform temperature profile was achieved using the simulation to provide the most uniform thickness distribution. Zimmer et al.
[17] used a similar free-blow method used for these experiments to assess the simulation accuracy. The analysis only concentrated on the patterned preform tip subjected to IR heating with no stretch-rod deformation and limited stretch ratios. Results revealed that the biaxial deformation behaviour was predicted in the simulation more successfully using the free-blow characterisation method as opposed to the previously established biaxial testing method. Bordival et al. [18] attempted to model the IR heating and blowing process together. The correlation of the blowing simulation with experimental results revealed that although the wall thickness results were accurate ( $15 \%$ error on mean thickness), the cavity pressure was not, possibly due to an inappropriate air flow model. Mir et al. [19] formed a stretch-blow -moulding simulation using Blowsim ${ }^{\circledR} \mathrm{FE}$ software and an elasto-viscoplastic material model with parameters identified using biaxial stretching data. Bottle formation was found to have good agreement with experimental results. However the validation was only performed for two bottle designs.

This paper intends to construct a suitable FSB simulation accounting for material temperature, air flow rate and material model for the behaviour of PET. A comparison of the FSB process can then be performed between the experiment and the correlating simulation over a large process window. The simulation accuracy was assessed by investigating the internal cavity pressure, stretch-rod reaction force, surface strain and bottle shape evolution. The paper is a significant advance in the current state of the art as it is the first time an ISBM simulation has been validated with detailed process data and strain values. Up till now all papers have produced ISBM simulations comparing final thickness distribution between simulation and experiment for a single process condition $[13,20,21]$. However they are not a full validation of the capability of a simulation. The true test is to validate the simulation over a wide range of parameters to ensure it highlights the trends correctly. The FSB trial may indeed be an 'incomplete' assessment of the true SBM process where there is no mould. The benefits of this however are evident as the FSB trials can reveal a full deformation investigation up to the point of mould contact providing detailed quantitative information for validation. Once a validated FSB simulation has been achieved and predicting the preform deformation can be relied upon, applying the mould is then a logical step to fulfilling the requirements of a successful SBM simulation.

\section{Simulation input parameters}

In order to build a suitable simulation of the FSB process, certain parameters and inputs must be defined. These include

- Preform geometry

- Thermal properties of PET 
- $\quad$ Preform temperature profile

- Stretch-rod velocity

- Air flow model

- Material model

\section{Geometry and idealisation}

The preform used throughout the analysis was $31.7 \mathrm{~g}$ with an internal throat diameter of $24.31 \mathrm{~mm}$ and a length of $97.16 \mathrm{~mm}$ (Fig. 1). The preforms were injected moulded using PET resin with an intrinsic viscosity of $0.81 \mathrm{dL} / \mathrm{g}$. The strain data point highlighted in Fig. 1 shows the location of the strain data comparison detailed in Section 3.3.

\section{Material temperature}

To simplify the preform heating procedure and to allow for greater control of the preform temperature profile, the preforms were heated using a Grant GR-150 silicone oil bath using a temperature range of $95{ }^{\circ} \mathrm{C}$ to $115^{\circ} \mathrm{C}$ with $5{ }^{\circ} \mathrm{C}$ increments. Heating times were applied to ensure full temperature equilibrium for the entire preform body which were then verified using a simple heat transfer simulation using ABAQUS, employing axisymmetric solid elements (DCAX4). For the simulation, the heat transfer coefficient during heating was $461 \mathrm{~W} / \mathrm{m}^{2} \mathrm{~K}$ [22] while the thermal conductivity and specific heat capacity for PET were taken from literature [23] where the values were a linear function of temperature (Table 1). The typical heating time to achieve temperature equilibrium through the preform thickness at $110^{\circ} \mathrm{C}$ was 3 min, Fig. 2 .

As a semi-automatic lab-scale SBM machine (Vitalli \&son) was employed, a manual transfer between the oil bath and the blowing station was required; the average time for this operation was $20 \mathrm{~s}$. A suitable heat transfer simulation was necessary to determine the temperature decrease of the preform during transfer. The heat transfer coefficient of the outer surface to air during cooling was experimentally derived using FLIR SC3000 thermal camera (operating wavelength 8$9 \mu \mathrm{m}$ ) allowing the preform to cool over time while recording the temperature reduction. This value was found to increase as a function of temperature (Table 1) and assumed a linear function over the temperature range. The heat transfer coefficient of the inner surface was fixed at $3 \mathrm{~W} / \mathrm{m}^{2} \mathrm{~K}$ due to the stagnant nature of the internal air cavity [24].

This was then supplied to a transient ABAQUS heat transfer simulation, employing axisymmetric solid elements of the preform geometry, and a complete preform temperature profile was obtainable at any given cooling time for any set oil temperature. Figure 3 shows the average outside surface temperature during cooling for three material temperatures, comparing the simulation with experimental results.

This predicted temperature profile relative to the preform height was then supplied to the ABAQUS free-stretch-blow (FSB) simulation using a nodal temperature definition. Table 2 displays the resultant average preform temperature from the cooling simulation for the oil temperature range. It should be noted that the results from the experimental analysis are presented relative to the oil set temperature, not the average preform temperature at the time of blowing. A study was conducted to assess the effect of using an average temperature applied over the shell thickness compared to a varying profile (5 integration points). Taking predicted cavity pressure as a reference, there was no difference between the two temperature scenarios. Applying the actual through thickness temperature profile to the simulation was found to have no significant difference compared to using an average through thickness temperature. This is a result of idealising the preform using
Fig. 1 Preform design and strain data extraction point for DIC routine

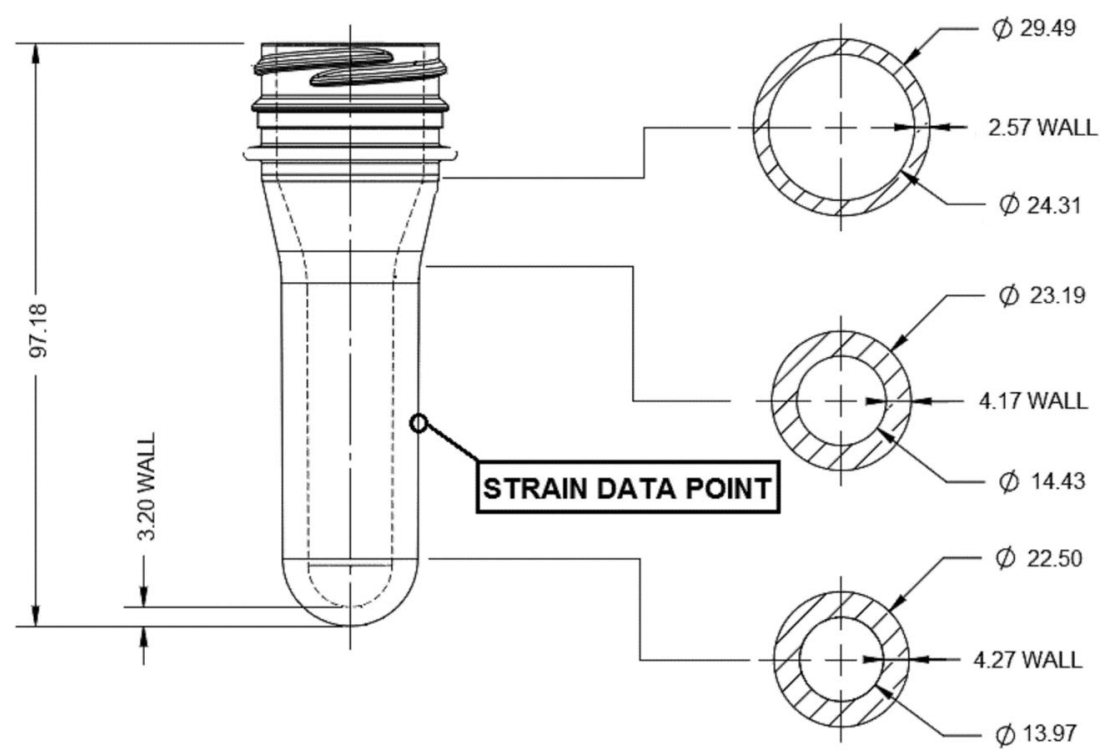


Table 1 Thermal properties of PET required for heating simulation

\begin{tabular}{llll}
\hline $\begin{array}{l}\text { Material } \\
\text { temperature } \\
\left({ }^{\circ} \mathrm{C}\right)\end{array}$ & $\begin{array}{l}\text { Thermal } \\
\text { conductivity } \\
(\mathrm{W} / \mathrm{mK})\end{array}$ & $\begin{array}{l}\text { Specific } \\
\text { heat } \\
\text { capacity } \\
(\mathrm{J} / \mathrm{kgK})\end{array}$ & $\begin{array}{l}\text { Heat } \\
\text { transfer } \\
\text { coefficient } \\
(\text { cooling }) \\
\left(\mathrm{W} / \mathrm{m}^{2} \mathrm{~K}\right)\end{array}$ \\
\hline 90 & 0.160 & 1601.40 & 9.42 \\
115 & 0.143 & 1677.13 & 12.99 \\
\hline
\end{tabular}

shell elements where the effect of temperature on the mechanical behaviour is averaged over the thickness. This is an acceptable inaccuracy considering the advantages of computational time and stability over solid elements.

Figure 4 displays the through thickness temperature derived from the cooling simulation after 20s transportation for the five node points (4 element layers) at sidewall midpoint (data extraction point) i.e. wall thickness $4.2 \mathrm{~mm}$. As previously mentioned, this was averaged for the purposes of the blowing simulation, while varying along the preform length. As the heating times were a matter of minutes, the silicone oil was assumed to have no effect on the structure or deformation of the preform.

The predicted temperature profile along the length of the preform outside surface was then plotted for the 20 s transportation at $95^{\circ} \mathrm{C}, 105^{\circ} \mathrm{C}$ and $115^{\circ} \mathrm{C}$, Fig. 5. Due to the oil bath heating method, the temperature profiles along the length were found to be almost linear; a clear advantage over IR heating where the temperature profile can fluctuate extensively. The predicted outside surface temperature profiles i.e. used for the simulation, were then confirmed using a FLIR SC640 thermal camera, Fig. 5. Along the main body of the preform $(20-70 \mathrm{~mm})$ the temperature was predicted to a high degree of accuracy (maximum error $2 \%$ ), while outside this range i.e.

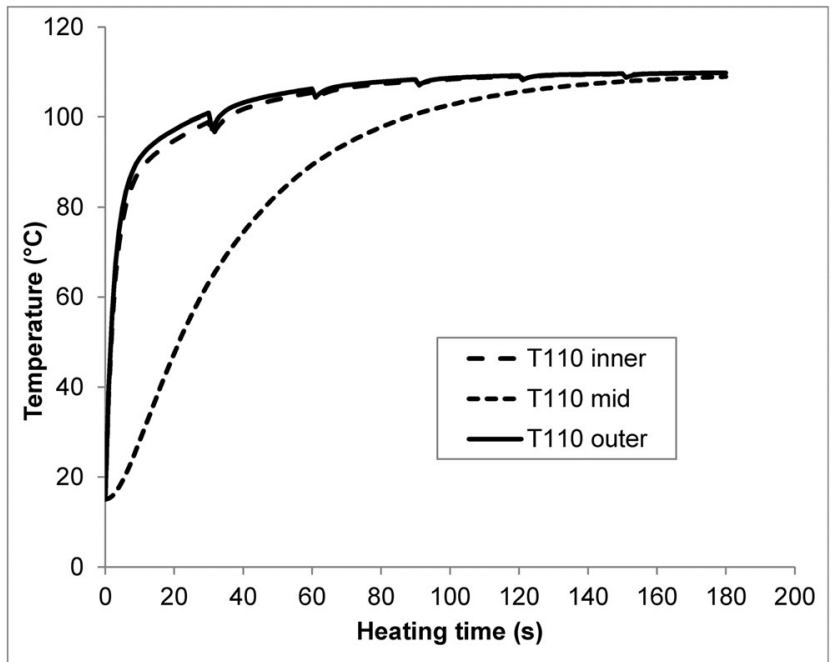

Fig. 2 Predicted preform heating profiles at $110^{\circ} \mathrm{C}$; inner, mid and outer preform layers

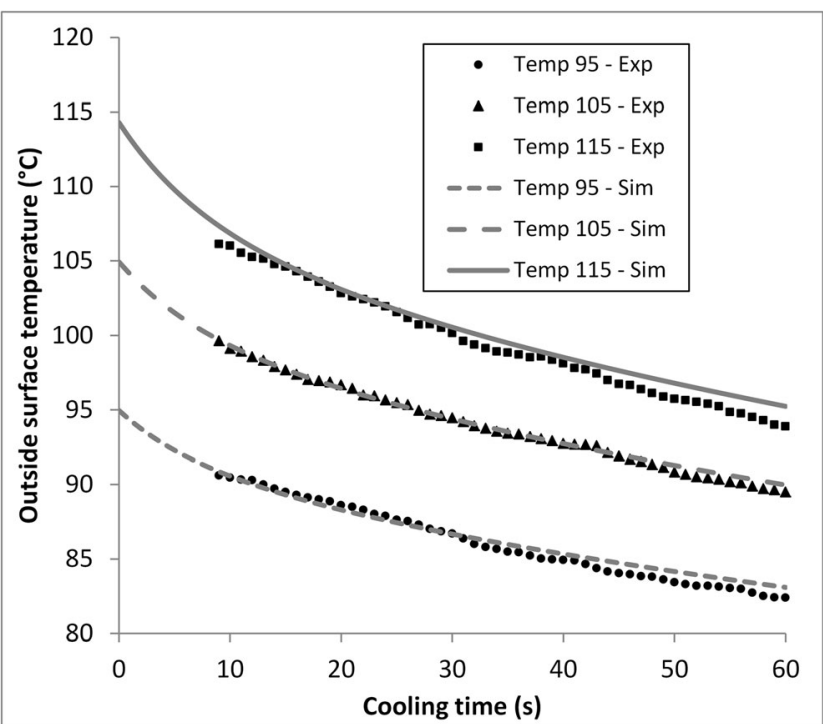

Fig. 3 Average outside surface temperature cooling for material temperatures $95^{\circ} \mathrm{C}, 105^{\circ} \mathrm{C}$ and $115^{\circ} \mathrm{C}$, predicted vs experimental

the neck taper and the tip, the accuracy decreased (maximum error $13 \%$ ). This was due to the angle of incidence between the preform surface and the IR camera deviated from normal and producing an effective reduction in emissivity [24] making the experimental measurements in the neck and tip region unreliable.

\section{Air flow rate}

In previous research by the authors [10,25], the amount of air flow rate governing the rate on inflation of the preform was shown to be an important variable. In these experiments the air flow rate could be varied by adjustment of the line pressure and adjustment of a flow restrictor which had dimensionless settings 0 to 6 i.e. closed to fully open. Figure 6 displays a schematic of the air flow circuit for the semi-automatic ISBM machine used in these experiments. For the purposes of these trials the line pressure was fixed to 8 bar and the flow restrictor input was set to 2,4 and 6 , corresponding to an air mass flow rate of 9,23 and $36 \mathrm{~g} / \mathrm{s}$ respectively. In previous research the

Table 2 Average preform temperature due to transportation cooling

\begin{tabular}{lll}
\hline $\begin{array}{l}\text { Oil } \\
\text { temperature } \\
\left({ }^{\circ} \mathrm{C}\right)\end{array}$ & $\begin{array}{l}\text { Resultant } \\
\text { average } \\
\text { preform } \\
\text { temperature }\left({ }^{\circ} \mathrm{C}\right)\end{array}$ & $\begin{array}{l}\text { Temperature } \\
\text { difference } \\
\text { through thickness }\left({ }^{\circ} \mathrm{C}\right)\end{array}$ \\
\hline 95 & 92.6 & 5.98 \\
100 & 97.45 & 6.83 \\
105 & 101.9 & 7.61 \\
110 & 106.46 & 9.16 \\
115 & 110.08 & 10.28 \\
\hline
\end{tabular}




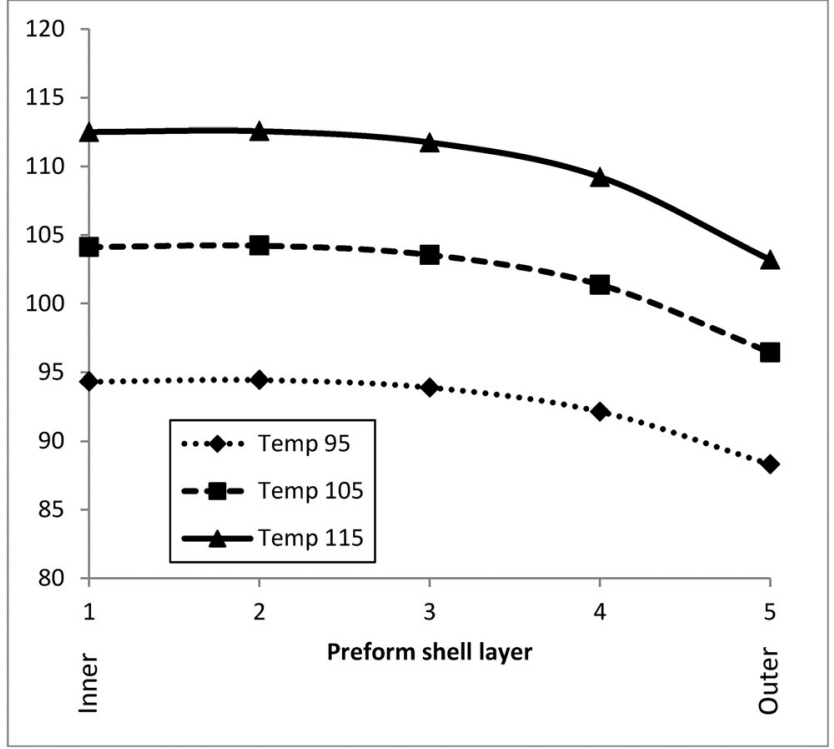

Fig. 4 Predicted through-thickness temperature profile for oil temperature $95^{\circ} \mathrm{C}, 105^{\circ} \mathrm{C}$ and $115^{\circ} \mathrm{C}$

evolving cavity temperature was recorded and revealed a quasi-adiabatic 'polytropic' process [25] and it was shown that assuming isothermal conditions was appropriate for accurately capturing the air flow behaviour.

Understanding this air flow is critical when forming a suitable FEA simulation. Schmidt et al. [26] used fixed volume experiments to ascertain the flow rate at a given pressure value. The air flow rate was then calculated from the pressure gradient achieved in the rigid cavity volume. The 'true' volume the air flow experiences, is in actual fact the preform volume and the volume of the pipework downstream of the control valve. This series of pipes, bends and orifices located between the flow control valve and the preform is defined as

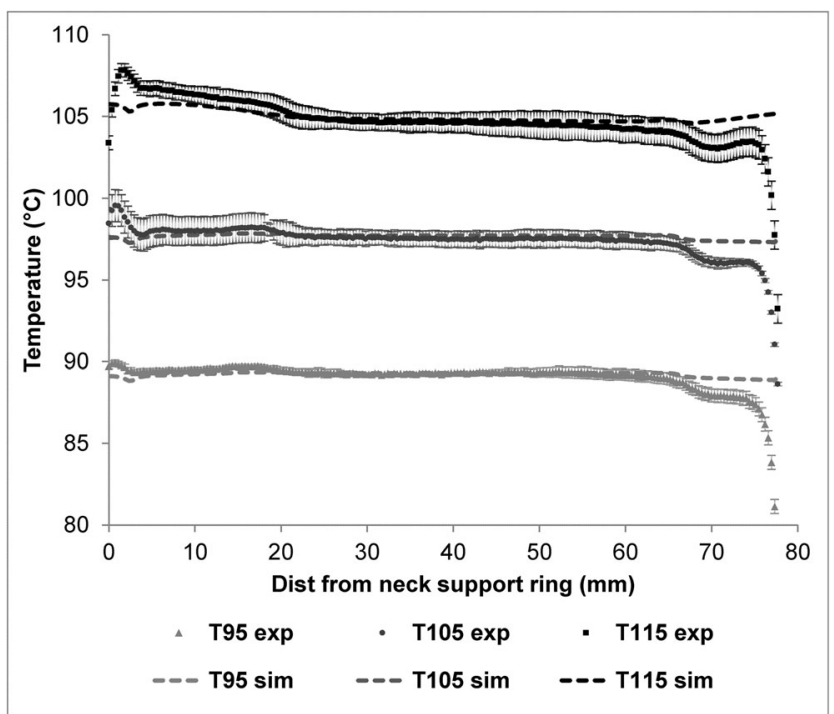

Fig. 5 Predicted temperature profile along the preform outside surface compared to experimental; $95^{\circ} \mathrm{C}, 105^{\circ} \mathrm{C}$ and $115^{\circ} \mathrm{C}$ the 'dead volume' $[6,27]$ and must be accounted for when supplying mass flow values to the simulation. The dead volume for the lab scale SBM machine used for these experiments was measured to be $85 \mathrm{ml}$ using the approach outlined in previous research [25]. The process data collected from experiment trials determined the flow rate characteristics; Fig. 7 shows the maximum choked mass flow rate value for numerous line pressures and flow indices determined using the ideal gas law method described by Salomeia et al. [25]. The choked flow assumption is only valid when the pressure ratio between upstream and downstream pressure is below 0.58. Above this, the flow becomes un-choked and the flow rate decays in a non-linear fashion to zero as the downstream pressure (preform cavity) matches the upstream pressure (line pressure) [25].

This air flow rate surface plot is only valid for the lab-scale SBM machine used for these experimental trials and a similar air flow rate investigation is required for each SBM machine where appropriate. This air flow rate characteristic can then be used as a key input for the FE simulation of the bottle forming process.

The air was regarded as a fluid with the appropriate properties using the *FLUID BEHAVIOUR keyword in Abaqus along with the polynomial type *CAPACITY using the Shomate equation where the constant pressure molar heat capacity can be expressed as Eq. 1 .

$\widetilde{C}_{p}=\tilde{a}+\widetilde{b}(T)+\widetilde{c}(T)^{2}+\widetilde{d}(T)^{3}+\frac{\widetilde{e}}{(T)^{2}}$

Where $\tilde{C}_{\mathrm{p}}$ is the constant pressure molar heat capacity, $T$ is the temperature and $\tilde{a}, \tilde{b}, \tilde{c}, \tilde{\mathrm{d}}, \tilde{\mathrm{e}}$ are the polynomial coefficients. The constant pressure heat capacity is then calculated using Eq. 2.

$C_{p}=\frac{\widetilde{C}_{p}}{M W}$

The polynomial coefficients for Eq. 1 where air is the fluid are shown in Table 3, [28].

\section{Constitutive model for PET}

A critical component for an accurate and reliable simulation is a suitable material model that can capture the non-linear, viscoelastic behaviour of PET when it is stretched. Yan et al. [29, 30] developed a constitutive model to represent the behaviour of PET during stretching; concentrating on the effects of polymer temperature, strain rates and mode of deformation. The model was implemented around the constitutive model developed by Buckley et al. [31, 32] that is widely used for thermoplastics near and above their glass transition temperature and incorporates a spring-dashpot assembly, Fig. 8 . 
Fig. 6 Schematic of air flow circuit

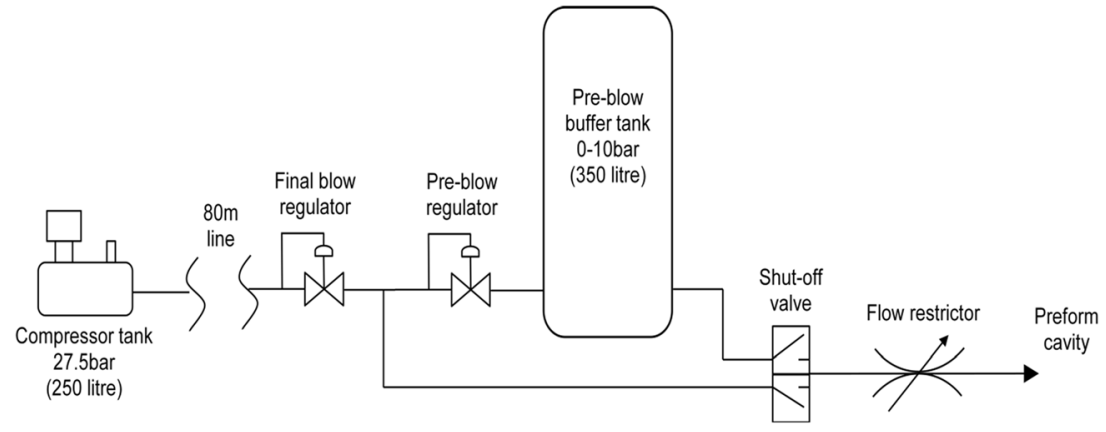

The model consists of a parallel circuit with two parts; a bond-stretch part representing the linear elastic deformation and the viscous flow, and a conformational part representing the non-linear elastic deformation of network stretch and the material viscosity. This was represented using the following set of equations [31, 32].

$\sigma_{i}=\sigma_{i}^{b}+\sigma_{i}^{c}(i=1,2,3)$

$\sigma_{i}=s_{i}^{b}+K^{b} \sum_{i=1}^{3} \epsilon_{i}+\sigma_{m 0}^{b}+\sigma_{i}^{c}$

$\sigma_{m}^{b}=K^{b} \ln (J)+\sigma_{m 0}^{b}$

Where $\sigma_{i}^{b}$ is the bond-stretching stress, $\sigma_{i}^{c}$ is the stress form conformational part, $s_{i}^{b}$ is the principal deviatoric stress of bond stretching part, $K^{b}$ is the bulk modulus of the bonded structures, $\epsilon_{i}$ are the principal true strain, $\sigma_{m 0}^{b}$ is a constant stress resident in the polymer as zero strain, $\sigma_{m}^{b}$ is the strain induced hydrostatic stress and $J$ is the determinant of the deformation gradient tensor. Deviatoric $\left(s^{b}\right)$ stresses exhibit viscoelasticity in terms of the deviatoric true strains $(e)$ in the bond stretching part.

$2 G^{b} \frac{d e}{d t}=\frac{d s^{b}}{d t}+\frac{s^{b}}{\tau}$

Where $G^{b}$ is the contribution to shear modulus arising from bond stretching and $\tau$ is the relaxation time. The free energy function for the conformational arm derived by Edwards and Vilgis is expressed by:

$A^{c}=\frac{N_{e} K_{B} T}{2}\left[\frac{(1+\eta)\left(1-\alpha^{2}\right)}{1-\alpha^{2} \sum_{i=1}^{3} \lambda_{i}^{n^{2}}} \sum_{i=1}^{3} \frac{\lambda_{i}^{n^{2}}}{1+\eta \lambda_{i}^{n^{2}}}+\sum_{i=1}^{3} \ln \left(1+\eta \lambda_{i}^{n^{2}}\right)+\ln \left(1-\alpha^{2} \sum_{i=1}^{3} \lambda_{i}^{n^{2}}\right)\right]$

Where $N_{e}$ is the entanglement density, $K_{B}$ is the Boltzmann's constant, $T$ is the absolute temperature, $\eta$ is the looseness parameter of the entanglement, $\lambda_{i}^{n}$ are the principal

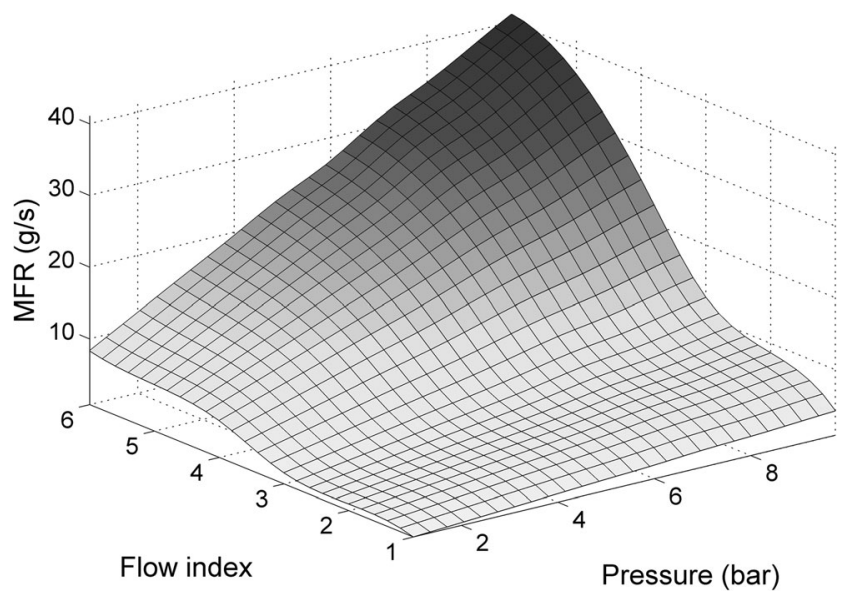

Fig. 7 Choked air mass flow rate for QUB ISBM machine network stretch and $\alpha$ is the measurements of the inextensibility of the entanglement network where the maximum extension is determined by $1 / \alpha$.

The adiabatic self-heating response evident when PET is rapidly stretched [33] was accounted for within the material model parameters i.e. the effect of self-heating was not isolated when characterising the material and therefore did not need to be reapplied to the model for the purposes of the simulation. The model developed by

Table 3 Polynomial coefficients for air fluid behaviour

\begin{tabular}{lc}
\hline Molecular weight $(\mathrm{kg} / \mathrm{mol})$ & 0.0289 \\
$\tilde{a}$ & 28.11 \\
$\tilde{b}\left(\times 10^{-3}\right)$ & 1.967 \\
$\tilde{c}\left(\times 10^{-6}\right)$ & 4.802 \\
$\tilde{d}\left(\times 10^{-9}\right)$ & -1.976 \\
$\tilde{e}\left(\times 10^{6}\right)$ & 0.0 \\
\hline
\end{tabular}


Fig. 8 Constitutive characteristic of the Buckley model $[31,32]$

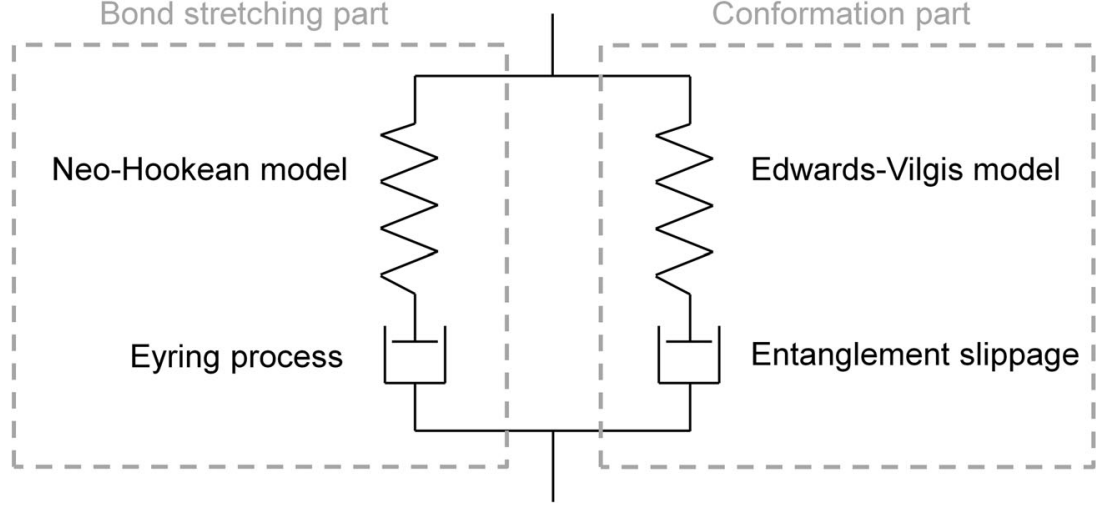

Yan was used for the purposes of these simulations using appropriate material constants [29] (Table 4).

\section{Simulation construction}

The simulation was constructed using axisymmetric shell elements (SAX1), with the elements representing the mid layer of the preform between the inner and outer surfaces, Fig. 1. The stretch-rod represented with rigid elements (RAX2) and

Table 4 Constitutive material model constants

\begin{tabular}{|c|c|}
\hline \multicolumn{2}{|l|}{ Bond stretching part } \\
\hline \multicolumn{2}{|l|}{ Eyring process } \\
\hline Shear activation volume $V_{s,}\left(m^{3} m o \Gamma^{l}\right)$ & $2.814 \times 10^{-3}$ \\
\hline Pressure activation volume $V_{p},\left(m^{3} \mathrm{~mol}^{l}\right)$ & $5.262 \times 10^{-4}$ \\
\hline Reference viscosity $\mu_{0}^{*},(\mathrm{MP} \alpha)$ & 1.71 \\
\hline Limiting temperature $T_{\infty},(K)$ & 328.76 \\
\hline Viscosity constant $C^{v},(K)$ & 67.47 \\
\hline \multicolumn{2}{|l|}{ Conformational part } \\
\hline \multicolumn{2}{|l|}{ Edwards-Vilgis model } \\
\hline Inextensibility parameter of entanglement $\alpha$ & 0.1553 \\
\hline Looseness parameter of entanglement $\eta$ & 0.001 \\
\hline Entanglement density $N_{s,}\left(\mathrm{~m}^{-3}\right)$ & $1.81 \times 10^{17}$ \\
\hline \multicolumn{2}{|l|}{ Critical network stretch } \\
\hline Superposition constant of $T_{\text {shift }} C_{1}$ & -0.0111 \\
\hline Superposition constant of $T_{\text {shift }} C_{2}$ & 3.627 \\
\hline Superposition constant of $T_{\text {shift }} \beta$ & 0.9856 \\
\hline Slope of linear line $k$ & -0.0356 \\
\hline Intercept of linear line $b$ & 15.393 \\
\hline \multicolumn{2}{|l|}{ Entanglement slippage viscosity } \\
\hline Reference viscosity $\gamma_{0}^{*},(M P \alpha)$ & 0.653 \\
\hline Limiting temperature $T_{\infty},(K)$ & 95.48 \\
\hline Viscosity constant $C^{s},(K)$ & 10612 \\
\hline Superposition constant of $T_{e} C_{1}$ & 0.157 \\
\hline Superposition constant of $T_{e} C_{2}$ & 39.94 \\
\hline Superposition constant of $T_{e} \beta$ & 0.9878 \\
\hline
\end{tabular}

the volume of the stretch-rod was not considered as part of the fluid cavity volume. The fluid cavity is a combination of the preform cavity and the dead-volume cavity i.e. the volume of the pipes upstream of the preform [25]. The volume of the stretch-rod relative to the full cavity volume was extracted from the simulation and found to only be a maximum of $8 \%$ (Fig. 9) at the start of the blowing process reducing $t$ $2 \%$ when the preform expands.

The resolution of the shell elements was $1 \mathrm{~mm}$ at the beginning of the simulation. Figure 10 displays the simulation set-up with dead volume, preform clamp, preform and stretchrod geometry.

The stretch-rod displacement was supplied directly from the experiment, recorded using a linear variable differential transformer (LVDT). The temperature of the preform was retrieved from the heat transfer simulation described in Section 2.1 and the correct air flow data relative to the flow restrictor setting was supplied. A simple Coulomb friction value of 0.3 [34] was used for contact between the stretch-rod tip and the polymer using the PENALTY contact constraint in ABAQUS with no

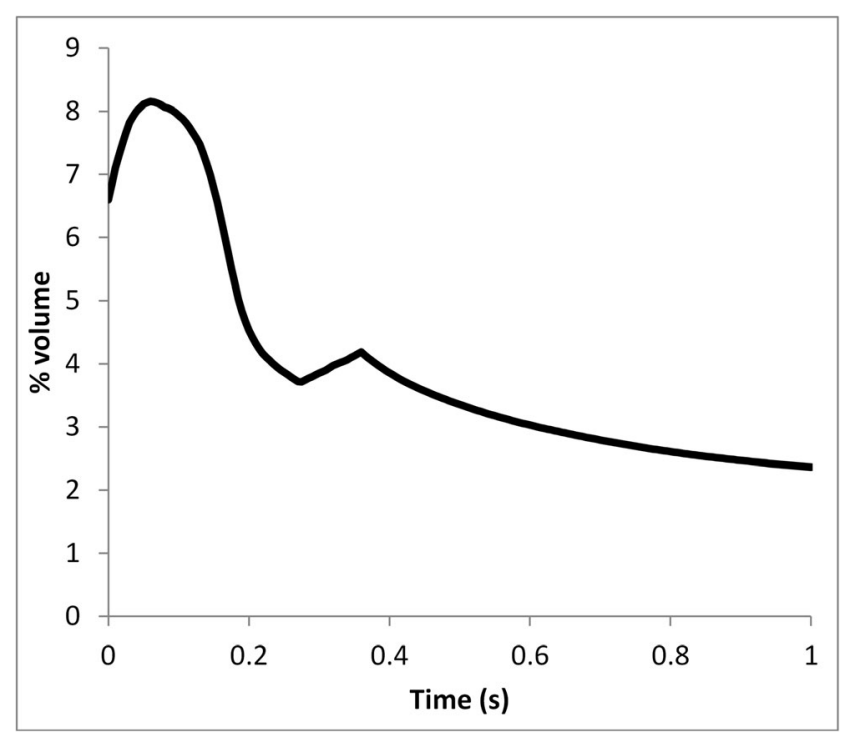

Fig. 9 Relative volume of stretch-rod in the fluid cavity during the blowing process 

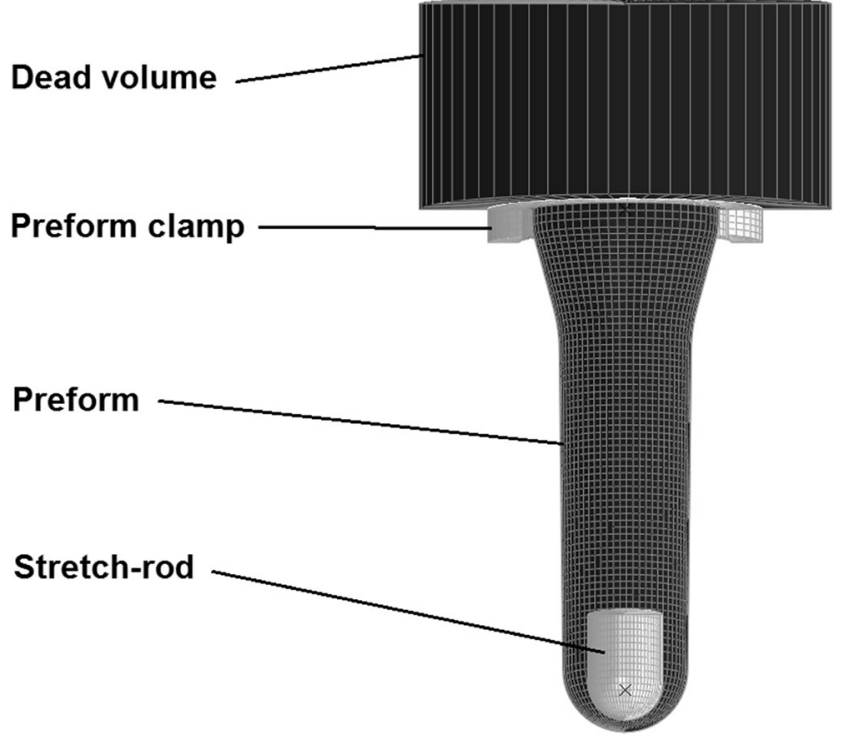

Fig. 10 Simulations set-up

heat transfer assumed. Assuming no heat transfer between the stretch-rod and the preform was deemed suitable considering the base of the bottle was not investigated.

A Design of Experiments of 15 trials was utilised for the simulation involving 5 oil temperatures and 3 air flow rates. The supply line pressure was fixed for all tests at 8 bar. Each test was labelled according to the temperature and flow rate e.g. N2T95 represents a flow index of 2 and oil temperature of $95^{\circ} \mathrm{C}$.

\section{Simulation validation}

The cavity pressure, stretch-rod force and surface strain results were captured for each experiment; the outcome of which produced a 'fingerprint' plot for each of the trials. Figure 11

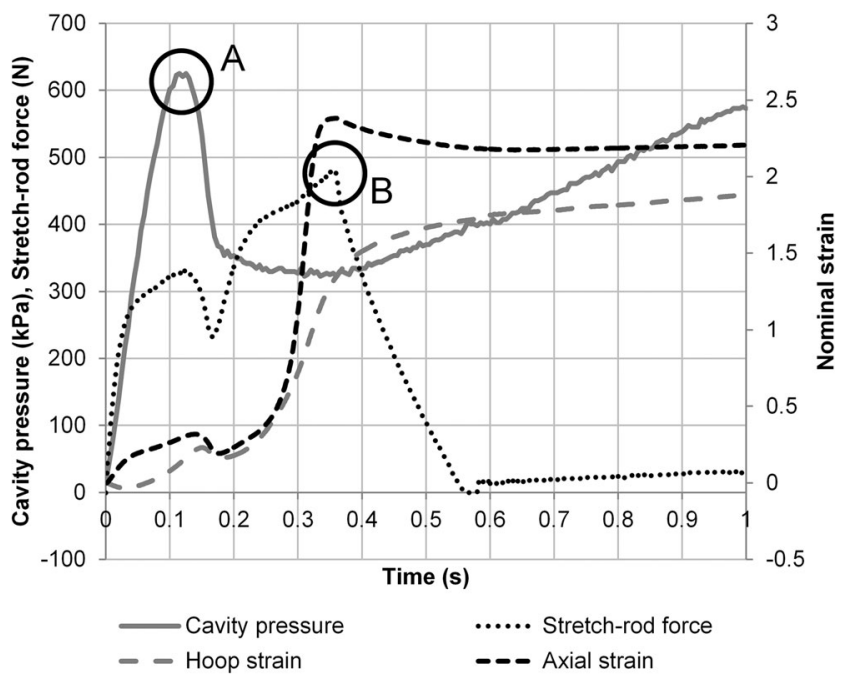

Fig. 11 'Fingerprint' plot for FSB trial; flow index 2, oil temperature $105^{\circ} \mathrm{C},(\mathrm{N} 2 \mathrm{~T} 105)$ highlights such data for a test conducted at flow index 2 and an oil temperature of $105{ }^{\circ} \mathrm{C}$. All experimental data obtained from the FSB trials are detailed by the author in a complementary publication [35].

Time zero of the fingerprint indicates the simultaneous contact of the stretch-rod with the preform tip and the introduction of the air flow i.e. no pressure advance or delay.

A reliable and repeatable method of comparing the simulation results to that of the experiment was required that could indicate the accuracy of each simulation with each parameter. Figure 12 shows a comparison of cavity pressure, stretch-rod reaction force and surface strain for the single condition flow index 2 (equating to air mass flow rate $9 \mathrm{~g} / \mathrm{s}$ ) and oil temperature $105^{\circ} \mathrm{C}$. It is not practical to compare these graphs for all 15 experiments conducted. Instead key points were extracted from the various data with the trends between the simulation and experiments obtained and compared; these key points were peak pressure, peak stretch-rod force, maximum strain rate, the aspect ratio (Eq. 10) and the bottle shape comparison. The location of the strain extraction is shown in Fig. 3.

Figure 13 displays a typical bottle shape comparison for trial N2T105 between the FSB experiment and the corresponding simulation.

In addition to validating the key points of the process outputs, the quality of the fit between the simulation and the experiment for cavity pressure, stretch-rod force and strain with respect to time was analysed by calculating the root mean square error (RMSE), Eq. 8.

$R M S E=\sqrt{\frac{\sum_{t=1}^{n}\left(\hat{y}_{t}-y_{t}\right)^{2}}{n}}$

Where $\hat{y}_{t}$ is the predicted value, $y_{t}$ is the experimental value over the data points $n$. The accuracy of the predicted output compared to the experimental data was then determined by calculating the normalised root mean square error (NRMSE).

$\%$ NRMSE $=\left[\frac{R M S E}{y_{\max }-y_{\min }}\right] \times 100 \%$

Plotting this error value then allowed complete examination of all of the experiments from Table 5 providing comparable assessment of the correlation accuracy and reveal the accuracy of the simulation over the entire processing range.

\section{Cavity pressure}

A comparison of the peak pressure from the simulation trials was then performed relative to the experimental peak pressure (Fig. 14) i.e. point A on Fig. 11. 


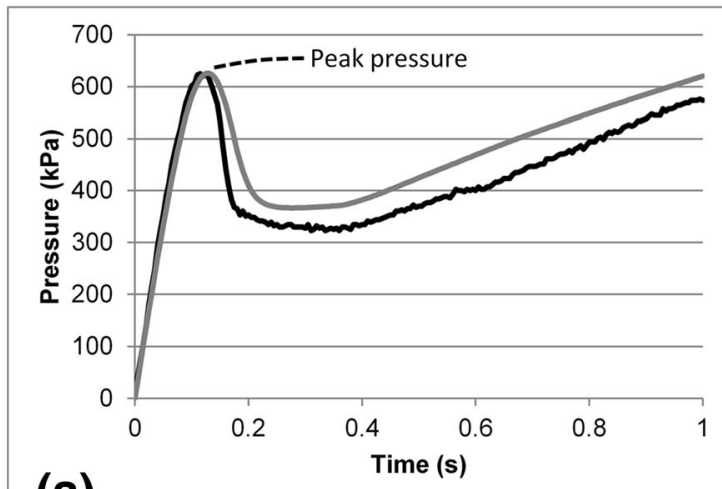

\section{(a)}

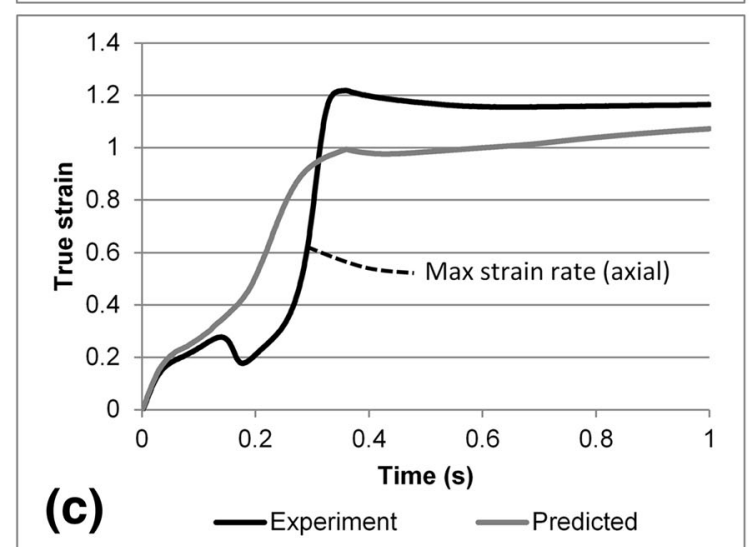

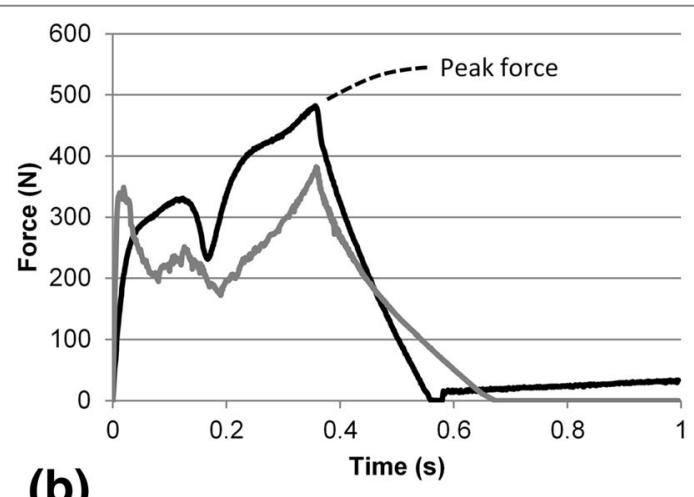

(b)

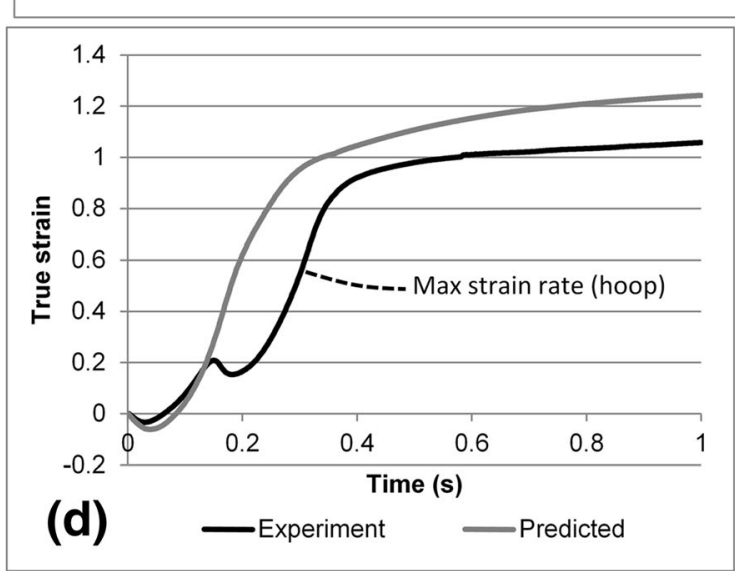

Fig. 12 Predicted results plotted with experimental results, trial N2T105; a pressure, $\mathbf{b}$ force, $\mathbf{c}$ axial strain and $\mathbf{d}$ hoop strain

The simulation peak pressure displays the same trend as experiment, mainly reducing with the increase in material temperature. The greater material temperature resulted in a more readily deformable preform that allowed for a faster volume expansion thus resulting in a lower pressure i.e. pressure is inversely proportional to volume. The effect of altering

Fig. 13 Bottle shape comparison for trial N2T105
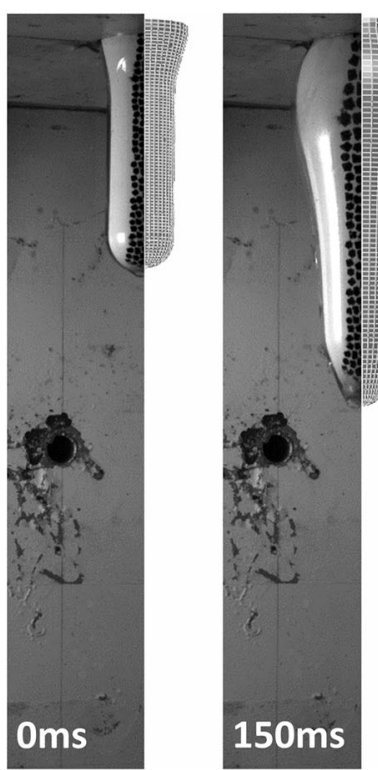

the flow index was also successfully captured by the simulation with a more significant decrease in peak pressure evident for the low flow index setting. The greater peak pressure at the higher flow index settings was due to the higher air mass flow rate. The greatest difference in peak pressure was observed for trial N2T115 with $13.5 \%$.

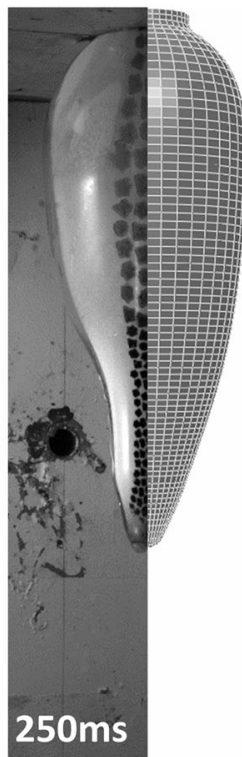

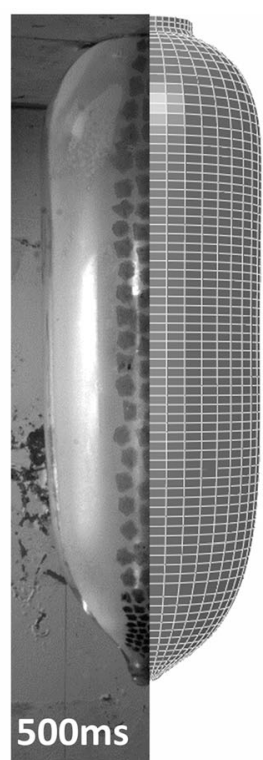


Table 5 Design of Experiment and test labels

\begin{tabular}{llrr}
\hline & \multicolumn{2}{l}{ Flow index } & \\
\cline { 2 - 4 } Oil temperature $\left({ }^{\circ} \mathrm{C}\right)$ & 2 & \multicolumn{1}{l}{6} \\
\hline 95 & N2T95 & N4T95 & N6T95 \\
100 & N2T100 & N4T100 & N6T100 \\
105 & N2T105 & N4T105 & N6T105 \\
110 & N2T110 & N4T110 & N6T110 \\
115 & N2T115 & N4T115 & N6T1115 \\
\hline
\end{tabular}

The \%NRMSE which highlights the difference between the overall pressure $\mathrm{v}$ time curve between the simulation and experiment is presented as a surface plot in Fig. 15. This illustrates the effect of material temperature and flow rate simultaneously, on the quality of pressure prediction.

The average amount of error apparent between the simulation and experimental cavity pressure was $8.54 \%$ with a minimum error of $5.68 \%$ for N2T100 and a maximum error of $15.43 \%$ for N2T115; in general, the low temperature trials were more accurate than the high temperature trials.

\section{Stretch-rod force}

The final peak force of the simulation (point B Fig. 11) was compared to the experimental data for all the process conditions highlighted in Table 5. Figure 16 highlights the trends for both simulation and experiments for the range of flow rates and oil temperatures investigated.

For both the experiment and the simulation, the peak end force reduced as the material temperature increased. This was as expected due to the increased preform deformability; indeed in some cases no stretch-rod force was recorded, indicating a purely pressure inflation deformation. This absence of

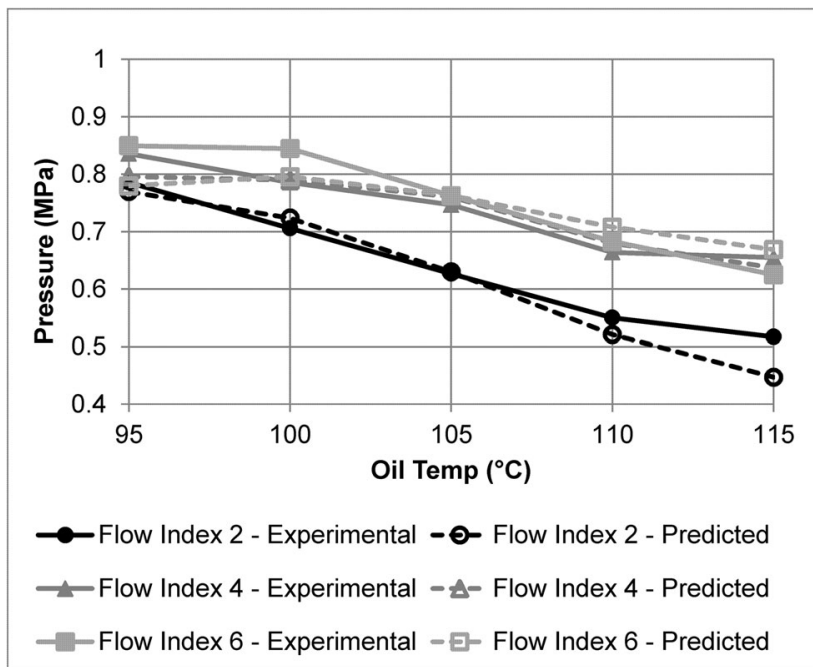

Fig. 14 Peak pressure comparison, experiment vs simulation

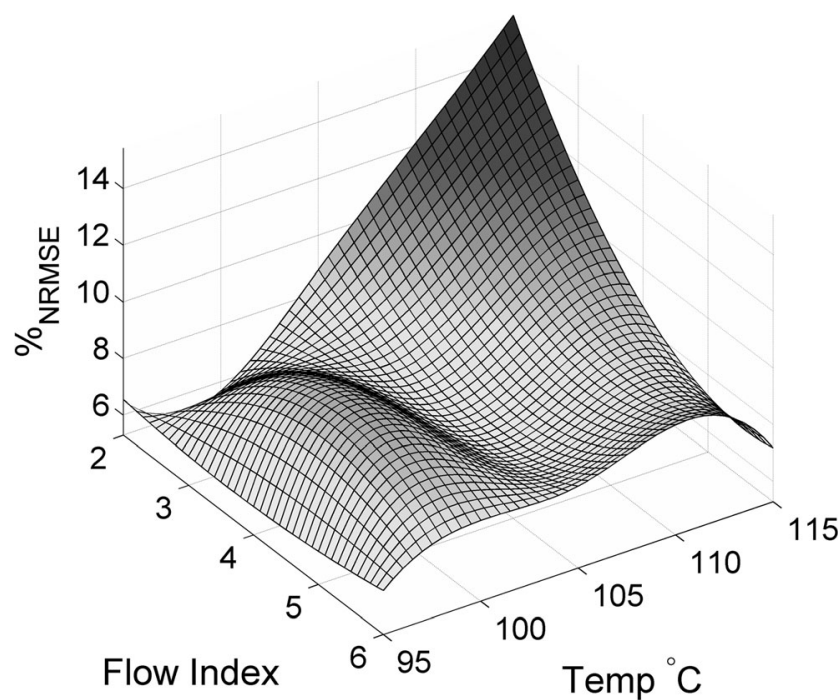

Fig. 15 Accuracy surface plots for cavity pressure varying temperature and flow rate

the final peak force was predicted correctly for trials N6T110 and N6T115.

The \%NRMSE comparing the overall quality of fit stretchrod force vs time between the simulation and experiment is presented using a surface plot, Fig. 17.

The average error observed for the predicted stretch-rod force was $26.84 \%$ with a minimum of $6.29 \%$ for N4T95 and maximum of $54.67 \%$ for N6T100. Overall, the average error was much greater than that calculated for the previous cavity pressure results, with no obvious trend in accuracy relative to either oil temperature or flow rate. This relative reduction in accuracy may be a result of an inadequate contact scenario model or the model's lack of ability to capture the anisotropic deformation behaviour prevalent in bottle manufacturing.

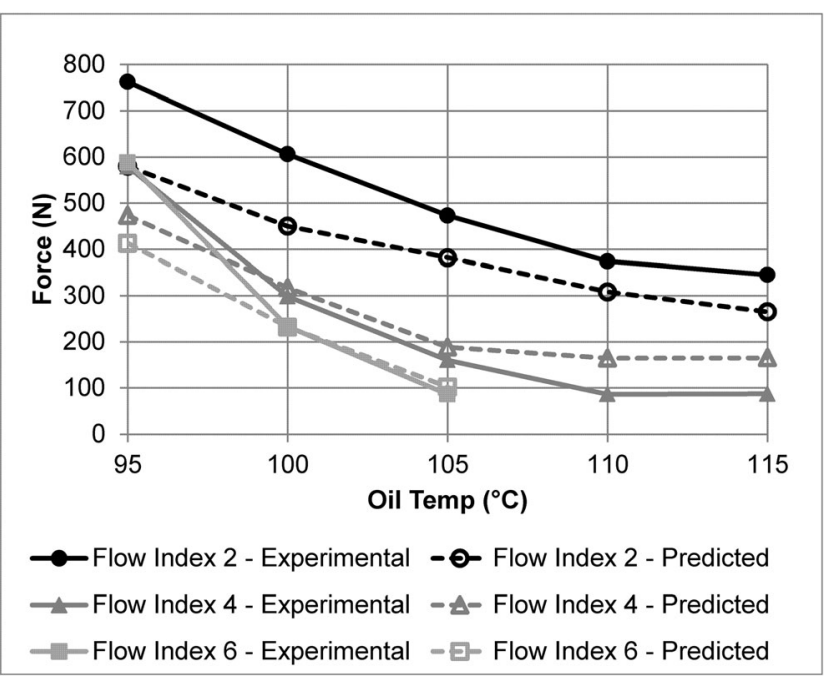

Fig. 16 Final peak force comparison, experiment vs simulation 


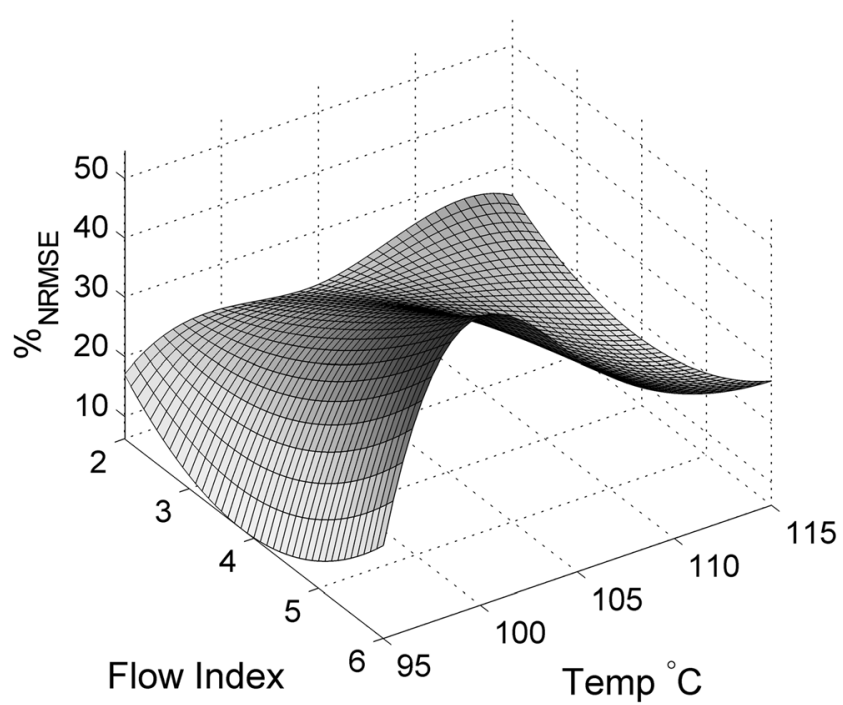

Fig. 17 Accuracy surface plot for stretch-rod force varying temperature and flow rate

\section{Surface strain rate}

The strain output direct from ABAQUS was relevant to the mid layer of the shell profile. In order to provide data to successfully assess the simulation, the outer layer strain output from the DIC routine was converted to mid layer strain to then compare with the mid (shell) layer of the simulation [36]. For the purposes of the material model, the assumption of material incompressibility was deemed suitable for the free-stretchblow tests, as detailed by Yan [29]. The strain comparison was determined using the midpoint of the sidewall of the preform, midway between the diameter change of the shoulder taper and the tip geometry, $43 \mathrm{~mm}$ from the neck support ring, Fig. 1.

The maximum strain rate was extracted from the simulation in the hoop and axial directions and compared to the DIC data extracted from the FSB experimental trials, Fig. 18.
The simulation hoop and axial strain rates were predicted with varying success. The predicted hoop strain rate increased as the temperature and flow rate increased with an average strain rate of $11.78,21.22$ and $26.78 / \mathrm{s}$ for flow index 2, 4 and 6 respectively, compared to average experimental results 13.1, 24.53 and 27.46/s. When examining the axial strain rate results, the predicted values were not as accurate as that of the hoop strain rate. A similar trend certainly appeared to be prevalent, where the strain rate increased as the temperature and flow rate increased with an average value of 13.86, 19.76 and 25.7/ $\mathrm{s}$ for flow index 2, 4 and 6 respectively, compared to average experimental results $42.91,45.12$ and $51.23 / \mathrm{s}$.

\section{Surface strain}

The strain levels from the data extraction point were then compared from the simulation and the experiment. The $\%$ NRMSE accuracy surface plots were then plotted regarding the strain vs time for each experiment, Fig. 19.

The average, maximum and minimum error was then determined for both hoop and axial strain results, Table 6 . The associated trials were also identified.

The average error observed was very similar for the hoop and axial trend accuracy plots. The maximum and minimum error values were also relatively comparable and were observed for similar process conditions; low accuracy (24.3\%) at low flow rate, high temperature and high accuracy $(0.9 \%)$ at medium flow rate, medium temperature.

\section{Natural aspect ratio}

The aspect ratio of the FSB bottle is a critical characteristic that can reveal the natural draw ratio in the axial and hoop direction. It is also a good indicator for industry to understand the optimum process conditions for a particular preform to
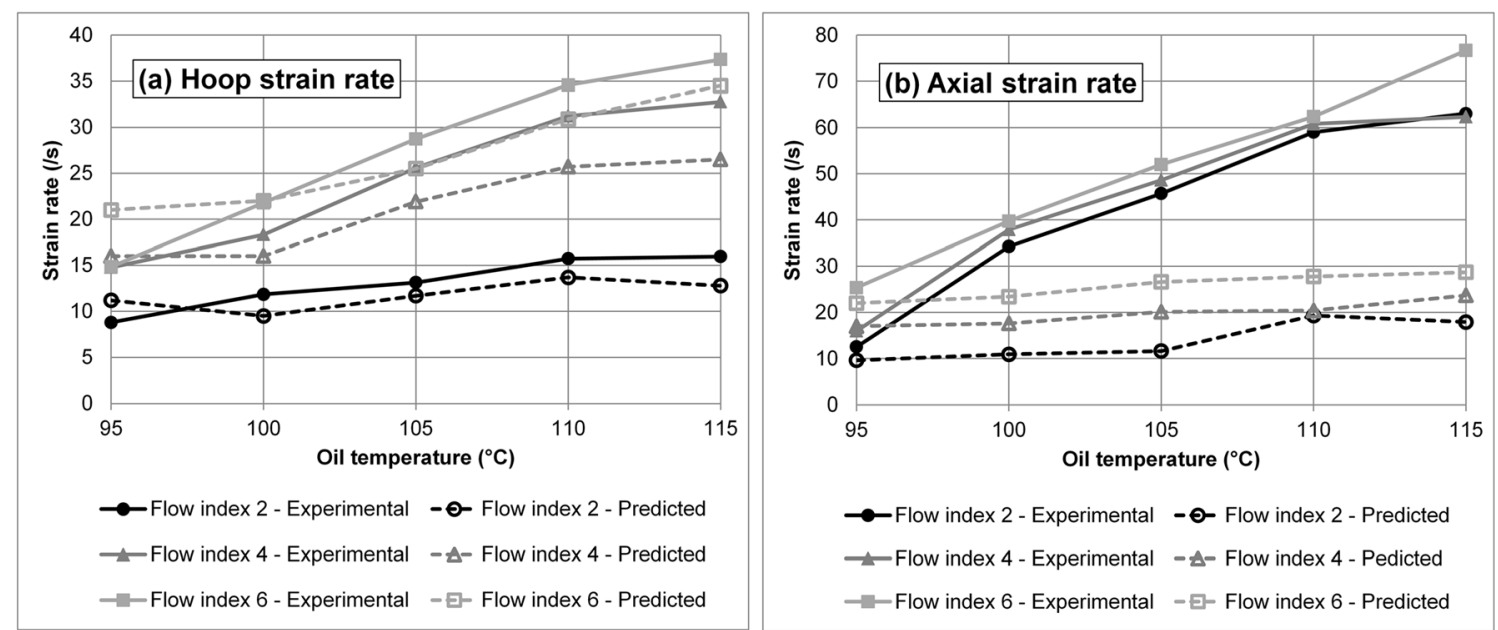

Fig. 18 Predicted maximum strain rate compared to experimental data; (a) hoop and (b) axial direction 
Fig. 19 Accuracy surface plot for strain data varying temperature and flow rate; (a) hoop and (b) axial direction (a)

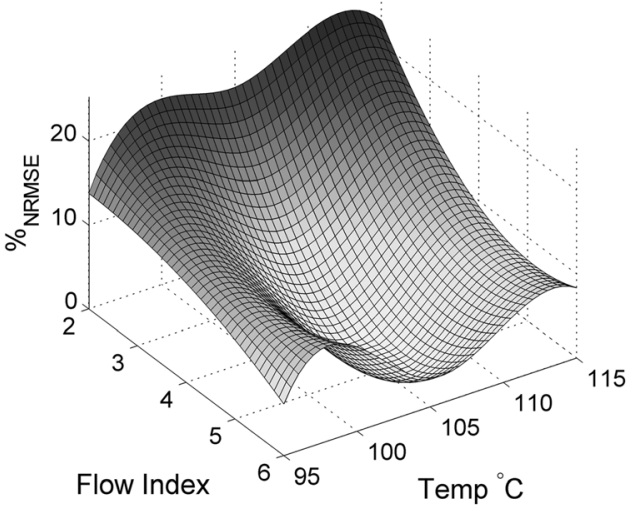

(b)

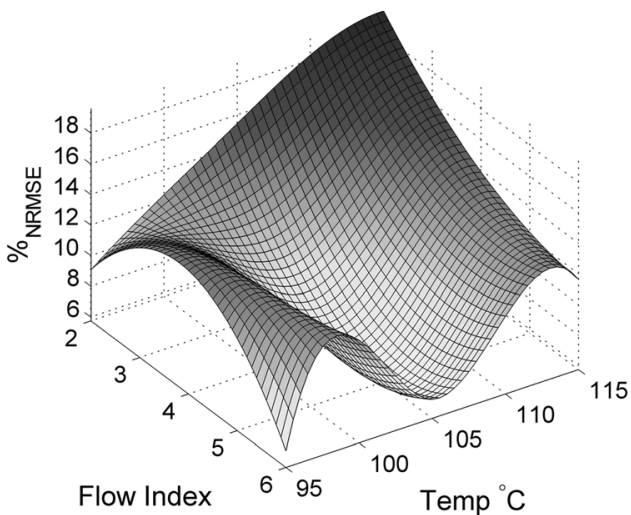

form a bottle where the aim is to have a natural aspect ratio similar to that of the mould. In this work the natural aspect ratio (Fig. 20) was taken to be the ratio of the vertical bottle length to the maximum bottle diameter, Eq. 10. The predicted aspect ratio was then compared to the experimental aspect ratio with the \% error calculated (Eq. 11), Fig. 20. It should be noted that the vertical length in essence will be highly influenced by the stretch-rod displacement; however aspect ratio will still be a function of the pressure inflation and overall preform deformation.

Aspect ratio, $A R=\frac{\text { vertical length }}{\text { maximum diameter }}$

\%error $=A B S\left|\frac{A R_{\text {sim }}-A R_{\text {exp }}}{A R_{\text {exp }}}\right| \times 100 \%$

The comparison in aspect ratio revealed a consistently accurate prediction for the higher flow indices $4(23 \mathrm{~g} / \mathrm{s})$ and 6 $(36 \mathrm{~g} / \mathrm{s})$ than for the lower flow index $2(9 \mathrm{~g} / \mathrm{s})$; the average \%error was $2.41,1.35$ and $8.9 \%$ respectively. The error experimental flow index N2 results increased as a function of temperature to a maximum error of $17.34 \%$ Fig. 21.

\section{Bottle shape comparison}

Although a great deal of insight was gained by capturing the internal cavity pressure, investigation into the

Table 6 Average, maximum and minimum \%NRMSE in true strain

\begin{tabular}{lll}
\hline & True hoop strain & True axial strain \\
\hline Average & $11.7 \%$ & $12.0 \%$ \\
Maximum & $24.3 \%(\mathrm{~N} 2 \mathrm{~T} 110)$ & $19.6 \%(\mathrm{~N} 2 \mathrm{~T} 115)$ \\
Minimum & $0.9 \%(\mathrm{~N} 4 \mathrm{~T} 105)$ & $6.8 \%(\mathrm{~N} 4 \mathrm{~T} 105)$ \\
\hline
\end{tabular}

shape of the evolving bottle was deemed necessary; cavity pressure only indicates cavity volume, not cavity shape. Figure 22 displays a comparison of the evolving bottle shape for both the experiment and simulation

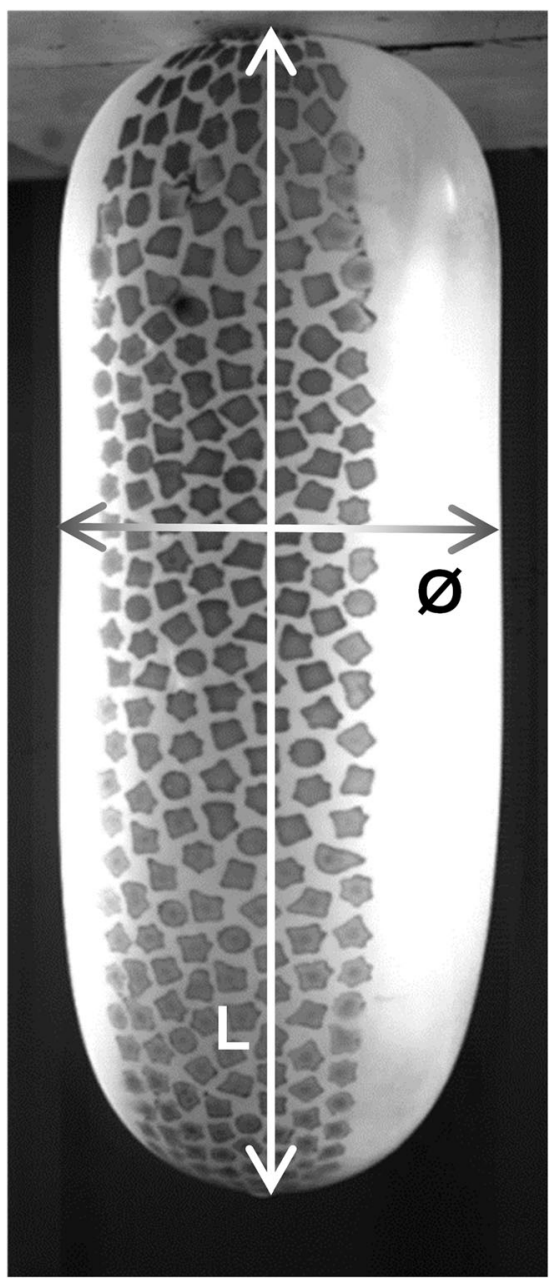

Fig. 20 Natural aspect ratio 


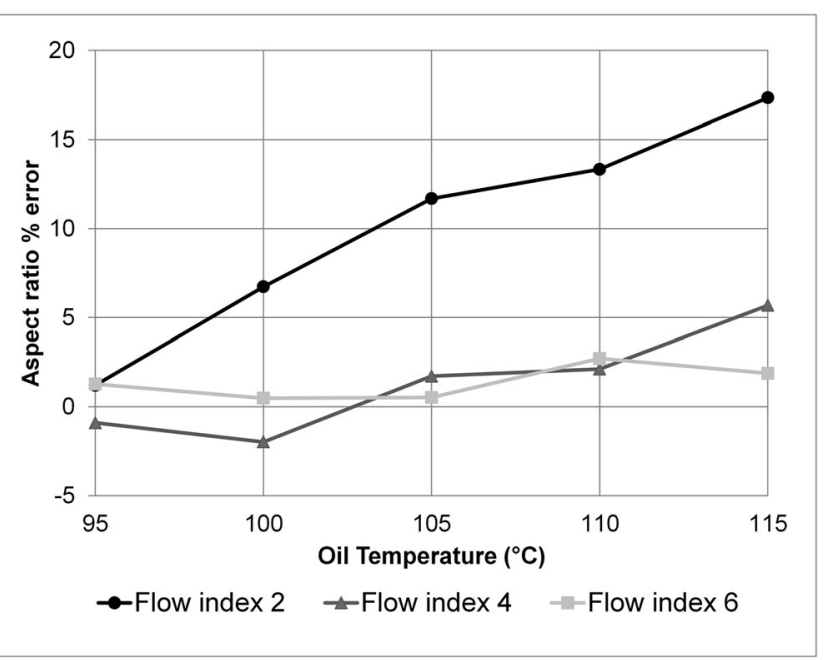

Fig. 21 Predicted aspect ratio compared to experimental results, \% error

along with the cavity pressure and surface strain investigating a 'high flow rate' trial (N6T105).

This particular trial was deemed most accurate with the predicted cavity pressure revealed successful correlation with a \%NRMSE of $3.9 \%$ while the average predicted strain
\%NRMSE of the hoop and axial results was $0.34 \%$. This combination of the accurate cavity pressure and strain results were then confirmed by the predicted evolving bottle shape from the high speed image stills. In contrast to this, the worst case scenario for the 'low flow rate' trial (N2T115) revealed a poor cavity pressure and strain prediction, Fig. 23.

Deemed the least accurate, this trial revealed a cavity pressure \%NRMSE of 18.06 and $17.02 \%$ for the strain accuracy. This low flow rate trial relies on a predominant linear stretch-rod deformation followed by pressure inflation while the high flow rate trial by nature has a more pressure derived deformation with a predominantly simultaneous biaxial deformation. It is the prediction of this sequential-type deformation that reveals a reduction in simulation accuracy.

Accurate cavity pressure may not necessarily reveal a successfully predicted bottle shape. Figure 24 displays the evolving bottle shape, internal cavity pressure and surface strain for trial N2T100.

The \%NRMSE for the predicted cavity pressure was calculated to be $5.91 \%$, while the average strain accuracy was $16.74 \%$. Thus the cavity pressure, and as a result the cavity volume, was predicted with high accuracy, however the
Fig. 22 Evolving bottle shape, cavity pressure and nominal strain, N6T105; comparison of experiment and simulation
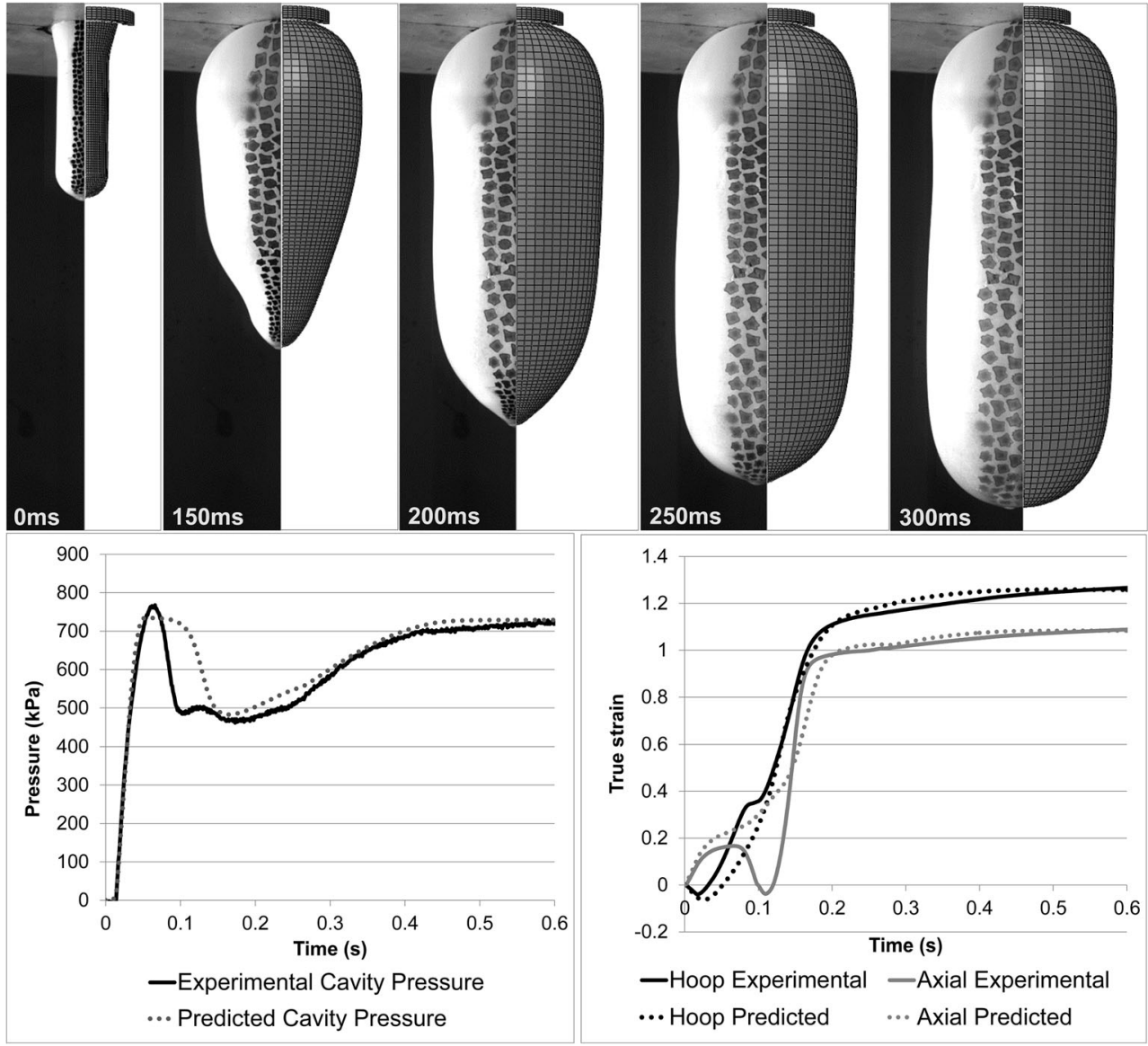
Fig. 23 Evolving bottle shape, cavity pressure and nominal strain, N2T115; comparison of experiment and simulation

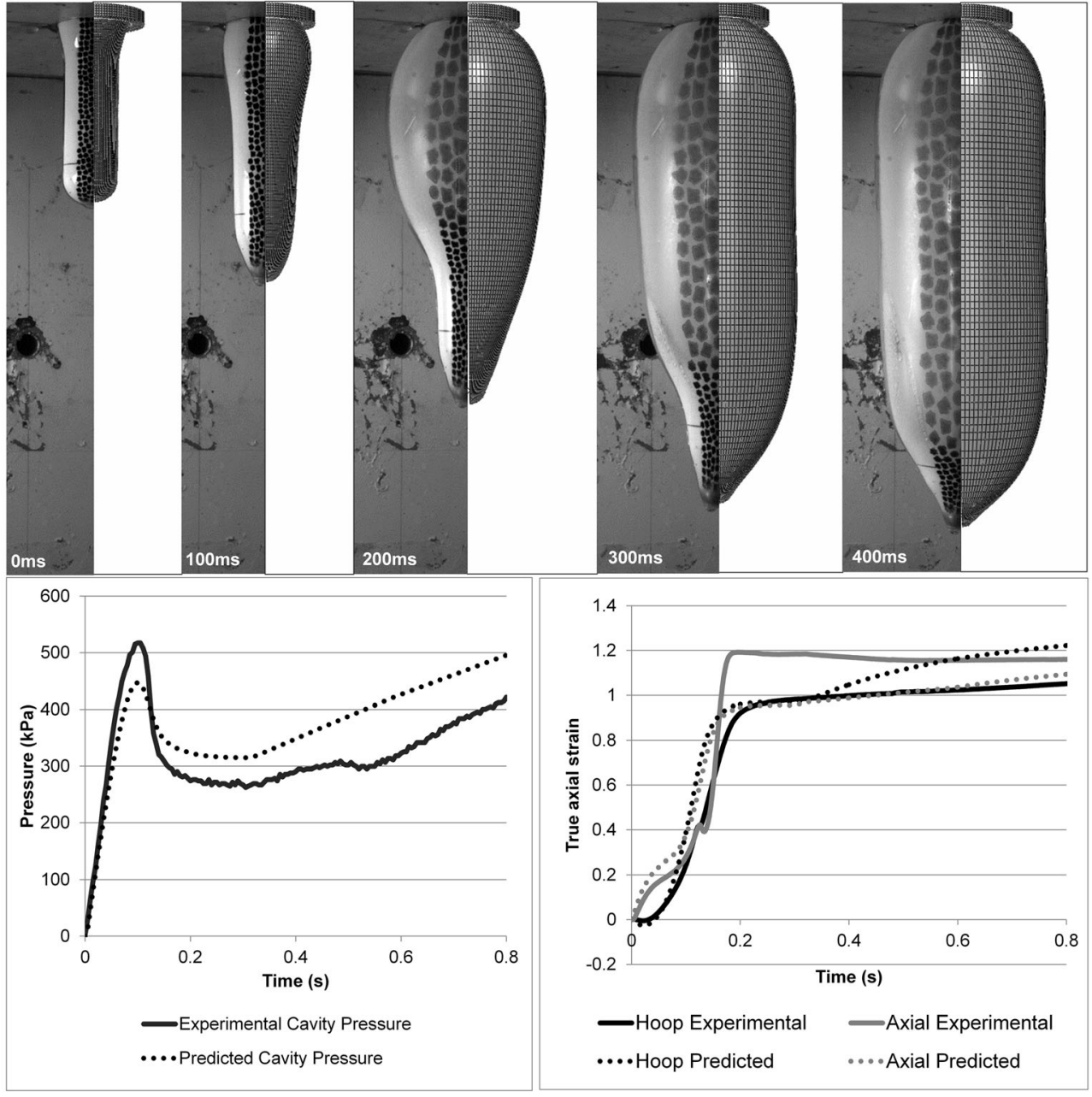

evolving bottle shape was not predicted as accurately; confirmed by the high speed image stills.

The reason for the difference in accuracy between these two cases is due to the difference in the mode of deformation experienced by the material. In the N6T105 trial the material is mainly deformed in a simultaneous biaxial manner i.e. hoop and axial strain increase simultaneously. However for the N2T100 trial he material is mainly deformed in a sequential biaxial manner i.e. a significant amount of strain occurs in the axial direction prior strain in the hoop direction. The difference in the mode of deformation causes a significant different stress-strain response from the material $[33,37]$, whereby the stress-strain response in sequential deformation is strongly dependent on the amount of initial stretch in the axial direction. This is a result of a mesophase being created in the initial stretching direction which significantly influences the second phase of stretching. The material model used in this simulation is able to successfully capture the simultaneous equal biaxial deformation but has difficulty in capturing the sequential behaviour $[29,30]$ hence the reason for the difference in accuracy between the two process conditions.

\section{Discussion}

Overall the simulation picks up the general trends well and makes a good qualitative prediction over the entire process range for cavity pressure, stretch-rod reaction force and surface strain. The only exception being the change in aspect ratio at the lower temperature and at low flow index. Quantitatively the simulation can predict the pressure vs time over the entire process range with an average error of $8.54 \%$ for all of the blowing trials. The stretch-rod force vs time prediction was less successful with an average error of $26.84 \%$ while the strain vs time prediction had an average error of $11.85 \%$. The average error in the predicted final aspect ratio of each bottle over the process range was $5.4 \%$. The purpose of this work however is not only to examine the quantitative accuracy of the simulation, but explore its ability to predict the trends that are observed during the experimental trials; a capability required to enable the simulation to be a useful design tool in industry.

Preform cavity pressure has generally been considered to be an indication to the bottle formation in both rate and size; previous research has also revealed that the cavity pressure is a 
Fig. 24 Evolving bottle shape, cavity pressure and true strain, N2T100; comparison of experiment and simulation

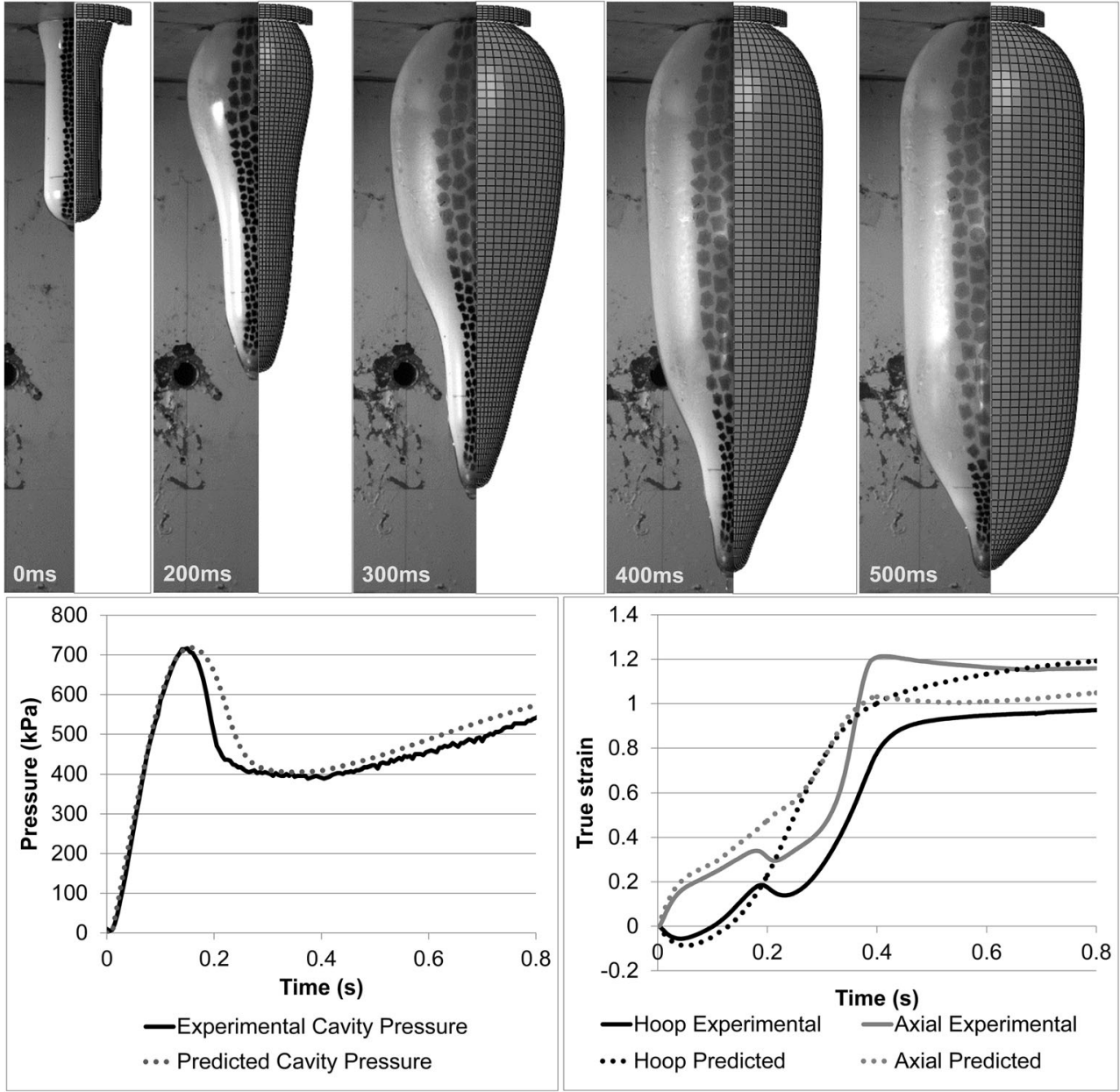

function of the line pressure, rate of air flow and preform expansion $[9,13]$. The simulation examined in this work reveals that cavity pressure is predicted with high accuracy for the process window analysed thus providing a good validation of the air flow model and the material model used in the simulation. The trends observed for the experimental peak cavity pressure reduced as a function of temperature and was successfully predicted by the simulation. This reduction in peak pressure corresponded to the increased deformability of the preform where the preform yielded earlier with increased temperature. Conversely, the trend of peak pressure magnitude was directly proportional to the increase in flow index where the greater air mass flow rate produced a higher peak cavity pressure. It must be stated however that the cavity pressure is only an indication of the rate of volume change, not the integral bottle shape and an accurately predicted cavity pressure profile may not necessarily yield an accurate bottle shape, as highlighted in Figure 24. This is important to note as the current state of the art in the industry relies on pressure vs time curves for process control. It is the comparative investigation into the strain output that details the accuracy of the predicted FSB bottle shape, and therefore the bottle shape and material distribution when re-applying the mould.
Qualitatively, the trend of the experiment peak force was well predicted by the simulation; where the peak force reduced both with increased temperature and flow index. The increased material temperature reduced the preform 'stiffness' resulting in reduced stretch-rod reaction force, while increased flow index (air mass flow) increased the pressure inflation rate and decreased the proportion of stretch-rod driven deformation. Quantitatively however, the predicted stretch-rod reaction force revealed as average of $26.84 \%$ error with the stretch-rod force under predicted for all investigated process parameters. Stretch-rod force was the result of many contributions; the contact scenario between the stretch-rod tip and the polymer, the heat transfer and the material reaction. There are several possible reasons to explain the difference in the quantitative force data. These include the fact that the simulation did not account for heat transfer between the rod and the preform tip. In reality there is a certain amount of tip cooling due to stretch-rod contact increasing the material stiffness and therefore the reaction force. The assumption of a single value of friction of 0.3 may also be insufficient as a suitable friction model in this complex contact scenario, especially when considering the film of oil present on the inside surface after oil bath heating. It is important to also note that the stretch-rod 
was actuated using a directly coupled pneumatic cylinder. An unfortunate side effect of this method was the inherent response for the stretch-rod to slow down due to a combination of the air compressibility and the choked air flow supplying the actuating cylinder. This effect was found to exacerbate as the preform temperature reduced i.e. the stiffer the preform material, the greater the stretch-rod speed reduction. Essentially, the simulation accuracy would be improved it the stretch-rod displacement was regarded as an output with the simulation input being the pressure value and flow of air into the stretch-rod actuation cylinder, similar to the preform cavity pressure.

The predicted values for strain rate were clearly restrained to some level lower than the experimental data; the maximum hoop and axial strain rates observed in the simulation was $34.5 / \mathrm{s}$ and $28.7 / \mathrm{s}$ respectively, while the experimental data revealed strain rates up to $37.3 / \mathrm{s}$ in the hoop direction and $76.7 / \mathrm{s}$ in the axial direction. This can be attributed to the limiting actuation speed (strain rate 32/s) of the biaxial stretching machine utilised for the material characterisation routine [30]. Qualitatively the hoop and axial strain rate values were predicted correctly for both the hoop and axial directions; the strain rate increased with increased material temperature, or more readily deformable preform. The strain rate also increased with increased flow index, where the increased air mass flow rate increased the rate of pressure inflation. Quantitatively however, the prediction of strain rate was less successful for the axial direction than for the hoop direction. A dramatic under prediction of axial strain rate was evident for all flow indices as the material temperature increased. The reason for the reduction in accuracy for the axial direction was primarily due to the nature of the deformation during the stretch-blow phase; a high dependency on linear stretchrod deformation (1st phase), followed by biaxial deformation from the 'delayed' pressure rise (2nd phase), where the 1st stretch phase greatly influenced the behaviour of the 2 nd stretch. The constitutive material model's ability to capture this sequential deformation mode proved to be reduced [29].

It is clear from the lower flow index trials that the dominant mode of deformation is sequential i.e. initial axial stretch by the stretch-rod followed by biaxial stretch in both hoop and axial direction when a critical combination of thickness and pressure is reached. In this scenario It has already been demonstrated that the material model is unable to predict this deformation mode as accurately compared to the scenario of simultaneous stretching and blowing.

The inadequacies of predicting the sequential deformation was also confirmed when comparing the bottle shape of the simulation and experiment with the final aspect ratio and the high speed image stills. The aspect ratio increased significantly for the experimental low flow index trials as the temperature increased; not predicted successfully by the simulation. The sequential nature of the low flow index trials was consequential to the inaccuracies of the material model to predict the final bottle shape. The amount of 1 st phase stretch relative to overall axial stretch for the low flow rate trial (N2T100) was double that of the high flow rate trial (N6T105); this large proportion 1st phase stretch heavily influenced the prediction of the sequential deformation mode. This result requires addressing in order to improve the material model and therefore improve the simulation accuracy over a wider process window.

\section{Conclusions}

A FSB simulation has been constructed correlating the previously established experimental trials using an oil bath heating method and free-blow machine. The trials have been conducted over a wide process window encompassing material temperature ranging from 95 to $115^{\circ} \mathrm{C}$ and air flow rates of 9,23 and $36 \mathrm{~g} / \mathrm{s}$.

The simulation accuracy was analysed comparing preform cavity pressure, stretch-rod reaction force and surface strain values revealed good correlation over the entire process window for all the variables analysed. Cavity pressure was accurately predicted both qualitatively and quantitatively for the entire processing range ensuring that the rate of volume expansion over time was also correctly predicted; cavity pressure is influenced by cavity volume not cavity shape. The cavity shape evolution was assessed using the high speed imagining and DIC routine where the bottle shape and fullfield strain map was determined, revealing maximum strain, strain rate and aspect ratio. Surface strain results and aspect ratio revealed reduced simulation accuracy at low flow rate trials i.e. trials with predominantly linear stretch-rod deformation followed by biaxial inflation. This was attributed to the nature of two phase deformation behaviour associated with sequential deformation and the inability of the material model to capture anisotropic behaviour. Stretch-rod reaction force prediction revealed reduced accuracy quantitatively due to an over-idealisation of the contact interaction between the preform and stretch-rod along with material model inaccuracies. Qualitatively however the stretch-rod reaction force vs time was predicted to a greater accuracy, successfully capturing the trends in the reaction force during the complete stretching phase of the preform.

The overall accuracy of the simulation to predict process parameters of the FSB experiment along with the evolving bottle shape has been rigorously examined and proved to have good correlation over the large process window presented.

\section{Compliance with ethical standards}

Conflict of interest None. 
Open Access This article is distributed under the terms of the Creative Commons Attribution 4.0 International License (http:// creativecommons.org/licenses/by/4.0/), which permits unrestricted use, distribution, and reproduction in any medium, provided you give appropriate credit to the original author(s) and the source, provide a link to the Creative Commons license, and indicate if changes were made.

\section{References}

1. Chaari F, Chaouche M, Douchet J (2003) Crystallization of poly(ethylene terephthalate) under tensile strain: crystalline development versus mechanical behaviour. Polymer 44(2):473-479

2. Gorlier E, Haudin JM, Billon N (2001) Strain-induced crystallisation in bulk amorphous PET under uni-axial loading. Polymer 42(23):9541-9549

3. Marco Y, Chevalier L, Chaouche M (2002) WAXD study of induced crystallization and orientation in poly (ethylene terephthalate) during biaxial elongation. Polymer 43(24):6569-6574

4. Bordival M, Schmidt FM, Le Maoult Y and Coment E (2007) Measurement of thermal contact resistance between the mould and the polymer for the stretch blow moulding process. In: ESAFORM, Zaragoza

5. Cakmak M, White JL, Spruiell JE (1985) An investigation of the kinematics of stretch blow moulding poly (ethylene terephthalate) bottles. J Appl Polym Sci 30(9):3679-3695

6. Salomeia Y, Menary GH and Armstrong CG (2008) Instrumentation of the stretch blow moulding process. In: Polymer Processing Society, Salerno

7. Haung HX, Yin ZS, Liu JH (2007) Visualisation study and analysis of preform growth in polyethylene terephthalate stretch blow moulding. J Appl Polym Sci 103(1):564-573

8. Billon N, Erner A and Gorlier E (2005) Kinematics of stretch blow moulding and plug assisted thermoforming of polymers; experimental study. Polym Process Soc

9. Menary GH, Tan CW, Picard M, Billon N, Armstrong CG and Harkin-Jones EM (2007) Numerical simulation of injection stretch blow moulding: Comparison with experiemtnal free blow trials. In: ESAFORM, Zaragoza

10. Nixon J, Yan S, Menary GH (2013) Analysis and simulation of the free-stretch-blow process of PET. Key Eng Mater 554-557:1729 1737

11. Nixon J, Yan S, Menary GH and Salomeia YM (2012) Understanding the Behaviour of PET in Stretch Blow Moulding. In: PMI2012, Ghent

12. Zimmer J, Detrois C and Stommel M (2013) Evaluation method for stretch blow moulding simulations with process-orientated experiemnts. In: Key Engineering Materials, Aveiro

13. Menary GH, Tan CW, Armstrong CG, Salomeia Y, Picard M, Billon N, Harkin-Jones EM (2010) Validating injection stretch blow moulding simulation via free blow trials. Polym Eng Sci 50(5):1047-1057

14. Menary GH, Armstrong CG, Crawford RJ, McEvoy JP (2000) Modelling of poly (ethylene terephthalate) in injection stretchblow moulding. Plast Rubbers and Compos 29(7):360-370

15. Yang ZJ, Harkin-Jones EM, Armstrong CG, Menary GH (2004) Finite element modelling of stretch-blow moulding of PET bottles using Buckley model: plant tests and effects of process conditions and material parameters. J Process Mech Eng 218(4):237-250

16. Bordival M, Schmidt FM, Le Maoult Y, Velay V (2009) Optimisation of preform temperature distribution for the stretchblow moulding of PET bottles: Infrared heating and blowing modelling. Polym Eng Sci 49(4):783-793
17. Zimmer J and Stommel M (2013) Method for the evaluation of stretch blow molding simulations with free blow trials. In: Material Science and Engineering

18. Bordival M, Schmidt FM, Le Maoult Y and Velay V (2007) Simulation of the two stages stretch blow moulding process: Infrared heating and blowing modeling. In: NUMIFORM, Porto

19. Mir H (2011) Modelling behaviour of PET for stretch and microblow moulding applicationsusing an elasto-visco-plastic material model. Int Polym Process 26(2):173-181

20. Cosson B, Chevalier L, Regnier G (2003) Simulation of the stretch blow moulding process: from the modelling of the microstructure evolution to the end-use elastic properties of polyethylene terephthalate bottles. Int J Mater Form 5(1):39-53

21. Yang ZJ, Harkin-Jones E, Menary GH, Armstrong GH (2004) Coupled temperature-displacement modelling of injection stretchblow moulding of PET bottles using Buckley model. J Mater Process Technol 153-154:20-27

22. Nixon J (2015) Analysis of the stretch blow moulding process and subsequent simulation development. PhD thesis, Queen's University Belfast

23. Lopez CM, Felisberti MI (2004) Thermal conductivity of PET/ (LDPE/AI) composites determined by MDSC. Polym Test 23(6): 637-645

24. Peeters J, Ribbens B, Dirckx JJ, Steenackers G (2016) Determining directional emissivity: Numerical estimation and experimental validation by using infrared thermography. Infrared Phys Technol 77: 344-350

25. Salomeia Y, Menary GH, Armstrong CG, Nixon J and Yan S (2015) Measuring and modelling air mass flow rate in the injection stretch blow moulding process. Int J Mater Form

26. Schmidt FM, Agassant JF, Bellet M (1998) Experimental study and numerical simulation of the injection stretch/blow moulding process. Polym Eng Sci 38(9):1399-1412

27. Salomeia YM (2009) Improved understanding of injection stretch blow moulding through instrumentation, process monitoring and modelling. $\mathrm{PhD}$ thesis, Queen's University Belfast

28. Simulia, Abaqus Analysis User's Guide - 11.5.2 Fluid cavity definition

29. Yan S (2013) Modelling the Constitutive behaviour of Poly(ethylene terephthalate) for the Stretch Blow Moulding Process. PhD Thesis, Queen's University Belfast

30. Yan S and Menary GH (2011) Modelling the constitutive behaviour of PET for stretch blow moulding. In: ESAform, Belfast

31. Buckley CP, Jones DP (1995) Glass-rubber constitutive model for amorphous polymers near the glass transition temperature. Polymer 36(17):3301-3312

32. Buckley CP, Jones DP (1996) Hot-drawing of poly(ethylene terephthalate) under biaxial stress: application of a three-dimensional glass-rubber constitutive model. Polymer 37(12):2403-2414

33. Menary GH, Tan CW, Harkin-Jones EM, Armstrong CG, Martin PJ (2011) Biaxial deformation and experimental study of PET at conditions applicable to stretch blow molding. Polym Eng Sci 52(3): 671-688

34. Bagherzadeh S, Bigiari FR, Nikbin K (2010) Parameter study of stretch-blow moulding process of polyehtylene terephthalate bottles using finite elements simulation. J Eng Manuf 224(8):1217-1227

35. Nixon J, Menary GH and Yan S. Free-stretch-blow Investigation of Poly(ethylene terephthalate) over a Large Process Window. UNDER REVIEW

36. Yan S, Menary GH and Nixon J (2016) A novel methodology to characterise the constitutive behaviour of aPET for the stretch blow moulding process. UNDER REVIEW

37. Menary GH, Tan CW, Armstrong CG (2012) The effect of temperature, strain rate and strain on the induced mechanical properties of biaxially stretched PET. Key Eng Mater 1117:504-506 